\title{
BALANCE SHEET EFFECTS, BAILOUT GUARANTEES AND FINANCIAL CRISES
}

\author{
Martin Schneider \\ Aaron Tornell \\ Working Paper 8060 \\ http://www.nber.org/papers/w8060
NATIONAL BUREAU OF ECONOMIC RESEARCH 1050 Massachusetts Avenue
Cambridge, MA 02138 \\ December 2000
}

\begin{abstract}
An earlier version of this paper circulated under the title "Lending Booms and Speculative Crises." We would like to thank Costas Azariadis, Philippe Bachetta, Ricardo Coballero, Jonas Fisher, Jeffrey Frankel, Mark Gertler, David Marshall, Monika Piazzesi, Assaf Razin, Tom Sargent, Andres Velasco, Annette Vissing-Jorgensen and seminar participants at Columbia, the Econometric Society Meetings, the NBER Summer Institute, the Federal Reserve Banks of Chicago and New York, NYU, Princeton, Stanford, Tel Aviv, and UCLA for comments and suggestions. All errors are our own. The views expressed herein are those of the authors and not necessarily those of the National Bureau of Economic Research.

(C) 2000 by Martin Schneider and Aaron Tornell. All rights reserved. Short sections of text, not to exceed two paragraphs, may be quoted without explicit permission provided that full credit, including $\odot$ notice, is given to the source.
\end{abstract}


Balance Sheet Effects, Bailout Guarantees and Financial Crises

Martin Schneider and Aaron Tornell

NBER Working Paper No. 8060

December 2000

JEL No. E32, E44, F32, F44

\begin{abstract}
Several recent 'twin' currency and banking crises were preceded by lending booms during which the banking system financed rapid growth of the nontradable $(\mathrm{N})$ sector by borrowing in foreign currency. They were followed by recessions during which a sharp decline in credit especially hurt the N-sector. This paper presents a model that accounts for these stylized facts. A crucial element is that we model a banking system that is simultaneously subject to two distortions typical of international credit markets: bailout guarantees and the imperfect enforceability of contracts. The interaction of these distortions produces unusually fast $\mathrm{N}$-sector growth, together with a real appreciation, during the boom. However, it is also responsible for self-fulfilling twin crises, which have persistent adverse effects on N-sector output.
\end{abstract}

Martin Schneider

Department of Economics

UCLA

405 Hilgard Avenue

Los Angeles, CA 90095

\author{
Aaron Tornell \\ Department of Economics \\ UCLA \\ 405 Hilgard Avenue \\ Los Angeles, CA 90095 \\ and NBER \\ tornell@econ.ucla.edu
}




\section{Introduction}

The 1990s have seen a number of boom-bust episodes in developing economies which share two broad features. First, the episodes were centered around 'twin' currency and banking crises, during which a real depreciation coincided with widespread problems in a banking sector financed with unhedged foreign-currency-denominated debt. Second, many crises were preceded by lending booms, during which bank lending fueled rapid growth of the nontradable $(\mathrm{N})$ sector, and followed by a sharp decline in credit that especially hurt the $\mathrm{N}$-sector.

To explain the first feature, 'third generation' crises models have looked to financial market imperfections as key 'fundamentals'. ${ }^{1}$ The models are typically based on one of two distortions: either "bad policy", in the form of bailout guarantees, or "bad markets", in the form of an imperfection that induces balance sheet effects, such as asymmetric information or the imperfect enforceability of contracts. While there has been some success in explaining twin crises, the profession still lacks a coherent account of a complete boom-bust episode, one which explains both features. ${ }^{2}$

This paper is an attempt to provide such an account. It differs from previous attempts in two important ways. First, we model a banking system that is simultaneously subject to two distortions in international credit markets: bailout guarantees and the imperfect enforceability of contracts, which induces balance sheet effects. Second, we stress the role of the nontradable sector, which is often overlooked in the debate about the causes of recent crises. The key effects stem from the interaction of the two distortions. During the boom this interaction relaxes endogenous borrowing constraints to permit unusually fast growth of the bank-dependent N-sector. However, it is also responsible for self-fulfilling twin crises, which have persistent adverse effects on N-sector output.

A number of stylized facts about the 'new' boom-bust episodes are now

\footnotetext{
${ }^{1}$ The Mundell-Fleming framework and traditional BoP crisis models are not appropriate for explaining these new boom-bust episodes, because the banking system plays no essential role in these models. In the standard Mundell-Fleming model, when there is a capital outflow the needed improvement in the current account can be attained with a real depreciation and with no output costs. According to this view, a depreciation induces a shift of resources from the nontradable to the tradable sector, and makes the economy more competitive in world markets. As a results growth resumes fast after the depreciation.

${ }^{2}$ We review the relevant literature in detail at the end of this section.
} 
widely agreed upon. Typically, the initial phase witnessed a real exchange rate appreciation and a lending boom, during which credit was growing unusually fast. ${ }^{3}$ To a large extent, international lending to the banking system was denominated in foreign currency. Much of this lending was also guaranteed by governments - at least implicitly. ${ }^{4}$ Twin crises often occurred in the absence of any major external shock and came as a surprise to financial markets. Dramatic real depreciations occurred along with widespread problems in the banking sector and substantial increases in bankruptcies. In most countries, rescue packages were designed to support the banking system and to bail out foreign lenders. Nevertheless, these countries still experienced a sharp decline in credit. ${ }^{5}$

In this paper, we emphasize two additional stylized facts about the Nsector. On the one hand, the performances of the tradable (T) and nontradable sectors have been remarkably asymmetric in many episodes. In particular, the N-sector has often grown faster before the crisis, fallen harder during crisis and recovered more slowly afterwards - as can be seen in Figure 1 . On the other hand, the banking system was often strongly exposed to the N-sector and many problems in the banking system originated in loans to that sector. ${ }^{6}$

The paper proceeds in two steps. We first introduce a simple microeconomic framework to study how banks, which lend to domestic firms, finance themselves in international credit markets. We consider a world in which $(i)$ contracts cannot be perfectly enforced and $(i i)$ there are bailout guarantees that insure lenders only against systemic — as opposed to idiosyncratic credit risk. Bailout guarantees apply to all types of debt. ${ }^{7}$ We show that, in this situation, banks may face binding endogenous borrowing constraints, even if their debt is guaranteed. ${ }^{8}$ This has two important implications for the

\footnotetext{
${ }^{3}$ Real appreciation has been particularly severe in Latin America. See Corsetti, Pesenti and Roubini (1998), Glick and Rose (1998), Gorinchas, et. al. (1999), Kaminsky and Reinhart (1999), Sachs, Tornell and Velasco (1995) and Tornell (1999).

${ }^{4}$ On both of these issues, see, for example, Bank for International Settlements (1998).

${ }^{5}$ As a concrete example of a boom-bust episode with these features, we describe below the Mexican experience around the December 1994 Tequila crisis.

${ }^{6}$ See, for example, Saunders and Wilson (2000) for the case of Mexico.

${ }^{7}$ Importantly, our analysis does not rely on either exogenously imposed borrowing constraints or an imposed preference for a particular denomination of debt.

${ }^{8}$ This is not an obvious point, given that the banking literature has shown that the two distortions typically affect lending in opposite directions, with deposit insurance leading to 'overlending', and contract enforceability problems to 'underlending'. In fact, if there was
} 
link between systemic credit risk and exchange rate risk.

On the one hand, if there is real exchange rate risk, it can be profitable for banks to implicitly colude and 'gamble' on the exchange rate. Indeed, an individual bank receives an implicit subsidy if it defaults in a state of systemic crisis, where lenders are covered by a guarantee. For a constrained bank, the subsidy effectively substitutes for scarce collateral and permits more borrowing, and hence profits. ${ }^{9}$ If many banks are exposed to the N-sector and gamble by denominating their debt in T goods (or 'foreign currency'), then a state of real depreciation will actually become one of systemic crisis. It follows that 'gambling' is actually optimal for an individual bank. Exchange rate risk is thus translated into systemic credit risk through bank debt denomination. ${ }^{10}$

On the other hand, if banks increase credit risk through debt denomination, exchange rate risk is endogenously created, as the economy becomes vulnerable to self-fulfilling meltdowns of the banking system. If the amount of $\mathrm{T}$ denominated debt is high, a real depreciation can severely squeeze cash flow, or even bankrupt banks altogether. Since they face binding borrowing constraints, they then have to curtail lending to the N-sector. Weak investment demand from the N-sector for its own products in turn validates the real depreciation. The systemic credit risk created by the banking system thus induces endogenous exchange rate risk. It follows that a 'sunspot' can trigger 'twin' crises, where severe real depreciation and widespread bankruptcies coincide. This 'crisis mechanism' can be activated whenever banks have accumulated a large amount of $\mathrm{T}$ denominated debt.

In a second step, we develop a dynamic model of a small open economy in which a T-debt-financed boom can end in crisis. The boom occurs because the N-sector anticipates a favorable demand shift in the future, which

a blanket bailout guarantee, such as full deposit insurance, then lenders would not care about contract enforceability in the first place. Balance sheet effects would be entirely neutralized by the guarantee. The reason this does not occur in our model is because bailout guarantees insure lenders only against systemic shocks. This assumption, which appears reasonable in the situation we are studying, implies that lenders still guard against idiosyncratic credit risk by rationing credit.

${ }^{9}$ The 'underlending' which is typical of a constrained banking sector is thus partially alleviated by the guarantee.

${ }^{10} \mathrm{We}$ would like to emphasize that allowing domestic banks to choose their debt denomination is realistic. Even if they were not able to issue debt indexed to the price of nontradables, they could buy an insurance against a systemic crisis. This has been done by some Argentinian banks in the aftermath of the Tequila crisis. 
might be due, for instance, to the effects of a reform. This encourages the Nsector to run a deficit and build up productive capacity. Deficits are financed through banks which in turn borrow from abroad. Growth is gradual, as borrowing constraints are relaxed only through the reinvestment of revenues. Absent bailout guarantees and adverse exogenous shocks, this type of transition period will simply see the relative growth of the N-sector, in anticipation of future profits, constrained, naturally, by the scarcity of collateral.

If bailout guarantees are present, their interaction with borrowing constraints both fuels the boom and induces endogenous volatility. Guarantees alleviate the 'underinvestment' problem usually associated with constrained banks. They permit high leverage with debt denominated in $\mathrm{T}$ goods, and faster credit growth. As a result, the N-sector also grows faster than if guarantees were absent. Since N goods are demanded for investment by the $\mathrm{N}$-sector itself, both output and the relative price of nontradables increase during the boom. Indeed, since debt is denominated in $\mathrm{T}$ goods, a real appreciation (a relative price increase) increases banks' cash flow. For constrained banks, this translates into more lending through a 'balance sheet effect'. More lending, in turn, permits more investment in $\mathrm{N}$ goods, which absorbs the higher output.

However, the debt burden eventually becomes high enough so as to make the economy vulnerable to the twin crises described above. Importantly, such crises are not merely financial, but have substantial output costs: in the crisis period internal funds and investment demand collapse. This leads to a drop in N-sector output. Subsequently, balance sheet effects permit only a slow recovery. This provides an account of a complete boom-bust episode.

While the timing of crises in our model is triggered by a 'sunspot' process, the likelihood of a self-fulfilling crisis is not a free parameter. Indeed, crises must be rare events in order for them to occur in equilibrium. ${ }^{11}$ If the probability of crisis was not sufficiently low, borrowing constraints would not bind because lenders could break even simply by cashing in the bailout in the highly likely event of a crisis. Furthermore, low expected returns would deter firms from investing and borrowing in the first place.

The ex-ante likelihood of crises in our model is not zero. While a model with unanticipated crises may be sometimes useful, because it is technically

\footnotetext{
${ }^{11}$ We take this feature of the model as a check on the plausibility of our particular sunspot story. In fact, Gourinchas, et. al. (1999) find that in a large sample of countries, the probability that a lending boom ends in crisis is quite small.
} 
simpler, we believe that for understanding recent crises it is conceptually unsatisfactory. On the one hand, if crises are unanticipated, firms are indifferent between $\mathrm{T}$ and $\mathrm{N}$ debt. We would thus need to assume fragility. Only if crises are anticipated can we rationalize this fragility as a result of risky debt denomination. On the other hand, in our environment an economy with anticipated crises will behave differently: only if crises are anticipated can we make the point that growth is faster if bailout guarantees are in place.

The paper has clear implications about what 'fundamentals' are behind twin crises: both distortions play an essential role in generating boom-bust cycles. If there were only guarantees, self-fulfilling meltdowns could not occur because banks could easily borrow in case of a real depreciation. Only if debt is denominated in tradables (because of guarantees) and if banks are credit constrained can a drop in price be self-fulfilling, as it bankrupts banks and leads to a collapse in demand. In the absence of balance sheet effects, one could explain lending booms that feature risk taking through debt denomination only if there were some 'fundamental' source of shocks that creates substantial real exchange rate risk. Note, however, that in most of the recent crisis episodes it has not been possible to identify such shocks.

Conversely, if there were only enforceability problems, banks could not profit from risky debt denomination. Indeed, in the presence of bankruptcy costs, they would prefer to hedge real exchange rate risk by denominating their debt in nontradables. Clearly, in the absence of $\mathrm{T}$ debt self-fulfilling meltdowns cannot occur. While an economy with credit constraints only might experience gradual lending booms and 'hangovers' after a crisis, it again requires a fundamental shock to trigger a crisis. In contrast, if guarantees are also present, borrowers will create the risky debt structure that is required for self-fulfilling meltdowns to occur.

The generosity of bailout guarantees unambiguously increases the vulnerability of the economy. In contrast, this is not true for the severity of the contract enforceability problem. In fact, fragility exists only for an intermediate range of leverage. On the one hand, contract enforceability problems cannot be too severe if crises are to occur. If a country's banks have essentially no access to international credit markets, our crisis mechanism is not relevant. A certain extent of leverage must be possible to make a country vulnerable. On the other hand, if the banks's access to credit is too easy, they can always borrow if there is a real depreciation. Balance sheet effects must be strong enough for the mechanism to work.

At first sight, the existence of bailout guarantees might not look like a 
good candidate for distinguishing between emerging economies (where crises have happened recently), and less volatile developed economies. Here, however, one has to take into account another factor that is not explicitly modeled, prudential regulation. In many industrialized countries, while there is at least an implicit too-big-to-fail guarantee for large institutions in place, banks may not be able to run the highly risky strategies that generate fragility. The 'unchecked' effects of guarantees is what makes emerging economies special.

The paper is structured as follows. In the next two subsections we present a literature review and a sketch of the Mexican experience. Section 2 introduces the model. Section 3 considers the interaction of bailout guarantees and enforceability problems at the individual level. Section 4 integrates the credit market with the rest of the economy. Section 5 derives the safe and risky equilibrium paths. Finally, Section 6 presents the conclusions.

\subsection{Literature Review}

Several ingredients of the story told above have been examined previously in the literature. To our knowledge, this paper and Schneider and Tornell (1999), are the first to formally study bailout guarantees and a contract enforceability problem in a unified framework. ${ }^{12}$ Balance sheet effects as a propagation mechanism are at the heart of a large literature in macroeconomics, beginning with Bernanke and Gertler (1989). ${ }^{13}$ Recent applications in a two sector, open economy context include Aghion, Bacchetta and Banerjee (1999) and Caballero and Krishnamurthy (1999).

In Aghion et al. (2000) T-goods are produced using a country-specific factor, which is nontradable. In their setup it is the T-sector the one that is constrained by net worth, and there are no bailout guarantees. An increase in T-sector net worth has two effects. First, it relaxes borrowing constraints, increasing investment and future net worth. Second, if the supply of the nontradable input is sufficiently inelastic, it drives up the input's price. As T-sector wealth builds up, the second effects gains strength. Thus, there is a time when the real appreciation spell comes to an end and there is a deep real depreciation. Like the present paper, this model derives endogenous volatility from balance sheet effects. However, it does not explain the other features of recent episodes. In particular, it does not explain the asymmetric behavior

\footnotetext{
${ }^{12}$ Schneider and Tornell (1999) consider an economy with exogenous shocks, and focus on the behavior of prices of fixed-supplied assets (i.e., real estate).

${ }^{13}$ See Bernanke, Gilchrist, and Gertler (1999), Gertler and Rogoff (1990).
} 
of T-sector and N-sector outputs observed in recent episodes. Moreover, the model does not explain the risky denomination of debt.

Caballero and Krishnamurthy (1999) consider a three-period, two-sector economy with credit constraints. Like we do, they single out the N-sector as having more difficulties in obtaining external finance. They do so by assuming that it cannot borrow directly from abroad. This creates a distinction between an economy's international collateral, provided by the T-sector and domestic collateral, which the N-sector needs for borrowing from the T-sector. They show that N-sector firms do not have incentives to hedge against future uncertainty and that in a crisis, shocks can get propagated across sectors and amplified through collateral prices. In contrast to our story, bailout guarantees play no role and exogenous shocks are essential for crises to occur. Furthermore, the model is not designed to generate lending booms and real exchange rate cycles, as it is essentially static.

Bailout guarantees have been prominent in discussions of the Asian crisis. Corsetti, Pesenti and Roubini (1998), Krugman (1998), and Mckinnon and Pill (1987) emphasize the role of guarantees for over-investment and the behavior of asset prices. Burnside, Eichenbaum and Rebelo (2000) show that bailout guarantees discourage agents from hedging their foreign currency exposure. In their model, banks borrow in foreign currency and lend in domestic currency. Self-fulfilling devaluations are possible because a devaluation transforms government's contingent liabilities into actual liabilities and depletes government reserves. Their model does not fit the other stylized facts because it does not give rise to credit constraints and it considers a one-sector economy and no output growth. In particular, there are no real exchange rate cycles, no meltdowns of balance sheets, and no credit crunch in the aftermath of crises.

In terms of the 'crisis mechanism', the papers most related to ours are Calvo (1998) and Krugman (1999). They also argue that, with risky debt denomination, balance sheet effects can be responsible for self-fulfilling meltdowns. In contrast to our work, they do not emphasize the role of the N-sector and simply assume the existence of foreign currency denominated debt and credit constraints. They consider neither the dynamics of lending booms nor the real exchange rate.

Following Obstfeld (1986), a number of other papers have described crises in models with multiple equilibria. Chang and Velasco (1998), and Cole and Kehoe (1997), emphasize coordination problems among lenders in the presence of short term debt. In these models, lenders refuse to roll-over debt 
because they fear others may also refuse to do so. Although this coordination failure can also occur in our model, it is distinct from the self-fulfilling real depreciations we emphasize in this paper. In particular, a model based only on coordination failure cannot account for the observed sectorial patterns and the persistent effects of crises.

In trying to explain the boom phase preceding a crisis, our work is related to a literature that has tried to rationalize key empirical regularities in the aftermath of stabilization in high inflation countries (e.g. Calvo and Vegh (2000), and Drazen and Helpman (1990)). This literature emphasizes the role of consumption and demand for real balances. Dynamics are driven by consumption decisions of agents that understand that the stabilization might fail in the near future. In this paper we focus on the role of bank lending.

\section{The Mexican Experience}

The experience of Mexico during the 1990s illustrates, in a rather sharp way, the facts mentioned in the Introduction. In the late 1980s, Mexico implemented radical trade and financial liberalization as well as deregulation and privatization programs. These policy measures generated the expectation of an extraordinary growth in exports after a short transition period. After decades of statism, the private sector was too small and so the relevant policy question was how to promote its rapid growth (as well as the investment in the infrastructure that would provide the services and inputs that the T-sector would need once the extraordinary future would arrive). The decision was made to privatize the banks and allow them to be the means through which resources would be channeled to the nascent private sector.

The expectation of an extraordinary growth in exports, as well as implicit bailout guarantees, generated privatization prices for the banks way above standard multiples-to-book value. As is well known, Mexico experienced a pronounced lending boom and a severe real appreciation. Between 1992 and 1994, lending from banks to the private sector increased by more than $50 \%$ in real terms and the real exchange rate appreciated around $15 \%$.

In December 1994, the new administration of President Zedillo announced a change in the exchange rate regime and engineered a small depreciation. Although the pre-crisis estimates of the real appreciation did not exceed $20 \%$, Mexico experienced a massive real depreciation of nearly $100 \%$. As a result, many firms were unable to repay their dollar denominated debts and the government had to implement a bailout program, known as the Fobaproa. 
Current estimates of the Fobaproa's costs are around 20\% of GDP.

In the aftermath of the Tequila crisis, real credit from banks to the private sector collapsed and has remained at a depressed level since then - as can be seen in Figure 2a. This stands in sharp contrast with the fast recovery of aggregate real GDP. Figure 2b shows how, after a short recession, real GDP started to increase as early as 1996. By 1997, it had recovered to its 1994 level.

Aggregate GDP performance masks an asymmetric sectorial response to the crisis. While the T-sector experienced an acceleration of growth throughout the period, the N-sector experienced a sharp fall and a sluggish recuperation. This asymmetric response was caused by the fact that the credit crunch affected mainly small and medium firms in the N-sector, while firms in the T-sector could obtain finance from international capital markets.

We use the evolution of manufactures and exports as proxy for the evolution of the T-sector. To proxy for non-tradables we look at construction. Figure 1 shows the asymmetric pattern of both sectors. Figure 2c shows how non-oil exports were not affected by the Tequila crisis. In fact, they increased at a faster rate thanks to the real depreciation and to the booming US economy.

The contrasting pattern displayed by the T- and N-sectors is consistent with the view that the real depreciation had a 'balance sheet' effect mainly in the N-sector. The destruction of entrepreneurial wealth, in turn, lead to the protracted recession in that sector and the credit crunch.

\section{The Model}

We consider a small open economy which exists for $T$ periods. There are two goods: an internationally tradable $(\mathrm{T})$ good, which is the numeraire, and a non-tradeable $(\mathrm{N})$ good. The only source of uncertainty is a sunspot variable $\sigma_{t}$ which is i.i.d. and takes values in $\{$ good, bad $\}$ with $\alpha$ probability of the 'good' state. ${ }^{14}$

\footnotetext{
${ }^{14}$ Two comments are in order. First, considering a two-sector economy is essential because the transfer of resources from the $\mathrm{N}$ - to the T-sector has played a leading role in recent crises, and because two sectors are needed to analyze the real exchange rate appreciation observed prior to the onset of crises and the asymmetric recovery in the aftermath of crises. Second, considering an economy with no fundamental uncertainty rules out explanations of crises based on the premise that emerging markets suffer from
} 
In this subsection we first describe preferences and technology. We then discuss the institutional features of emerging economies - which we capture through a particular 'credit market game' played by the agents - and define our notion of equilibrium.

\subsection{Preferences and Technology}

There are three types of agents in the economy: domestic consumers, foreign lenders, and managers.

\section{Foreign Lenders}

The role of foreign lenders in our model is standard. They are risk neutral and live for two periods. Moreover, they have 'deep pockets': they lend any amount of funds as long as they are promised the riskless world interest rate in expected value. Riskless bonds are issued by foreigners or consumers. They can be denominated in T-goods or in N-goods. A T-denominated bond pays one unit of tradables next period and trades today at the price $\beta:=\frac{1}{1+r}$, where $r$ is the constant world interest rate. An N-denominated bond pays $p_{t+1}$ units of tradables next period, where $p$ is the inverse of the real exchange rate, i.e. $p=\frac{p_{N}}{p_{T}}$. The N-bond trades today at the price $\frac{1}{1+r_{t}^{n}} .{ }^{15}$

Since the sunspot takes only two values, markets are complete as long as these two bonds are traded. In addition, the existence of risk neutral, 'deep pocket' lenders implies that uncovered interest parity must hold in any equilibrium, i.e.

$$
\left(1+r_{t}^{n}\right) p_{t+1}^{e}=1+r
$$

Here $p_{t+1}^{e}:=\alpha \bar{p}_{t+1}+(1-\alpha) \underline{p}_{t+1}$, where $\bar{p}_{t+1}$ and $\underline{p}_{t+1}$ denote the values that the price $p_{t+1}$ is expected to take on in period $t+1$ in the good and bad state, respectively. ${ }^{16}$ More generally, the price of every payoff stream will simply be its discounted expected value.

\section{Consumers}

more and bigger exogenous shocks than developed countries.

${ }^{15}$ Managers also issue bonds, but cannot commit to repay. Thus, in general, their debt will be risky, as will be described below.

${ }^{16}$ These values will depend on the information available at $t, \mathcal{I}_{t}: \bar{p}_{t+1}=$ $E\left[p_{t+1} \mid \mathcal{I}_{t},\left\{\sigma_{t+1}=\right.\right.$ good $\left.\}\right]$, and $\underline{p}_{t+1}=E\left[p_{t+1} \mid \mathcal{I}_{t},\left\{\sigma_{t+1}=b a d\right\}\right]$. 
There is a representative consumer that consumes tradable $\left(c_{t}^{t r}\right)$ and nontradable goods $\left(c_{t}^{n t}\right)$. His utility is

$$
\sum_{t=0}^{T} \beta^{t}\left[c_{t}^{t r}+d_{t} \log \left(c_{t}^{n t}\right)\right]
$$

Consumers are endowed with $\varepsilon$ units of the T-good in every period. In light of (1) and complete markets, their budget constraint is

$$
E\left[\sum_{t=0}^{T} \beta^{t}\left(c_{t}^{t r}+p_{t} c_{t}^{n t}-\varepsilon\right)\right] \leq 0
$$

As long as $\varepsilon$ is large enough (which we assume is the case), consumers' demand for $\mathrm{N}$-goods will be

$$
D_{t}\left(p_{t}\right)=\frac{d_{t}}{p_{t}}
$$

Reform (such as trade liberalization) or discovery of a natural resource (oil) induces a future outward shift in the demand for N-goods by the T-sector (offices, services, etc.). Typically, the expectation of future good-times is what drives lending booms. We capture this fact through a shift in the preference parameter $d_{t}$ :

$$
d_{t}= \begin{cases}d & \text { if } t<T \\ \hat{d} \geq d & \text { if } t=T\end{cases}
$$

The focus in this paper is on the N-sector. The 'consumer' is to be broadly interpreted as a stand-in for the T-sector. Our assumptions on preferences and absence of borrowing constraints is perhaps most natural if we imagine that the consumer is the owner of an exporting sector business, and the endowment $\varepsilon$ can be easily collateralized because it is tradable. What is important for our overall story is that there is a downward-sloping component of the demand for N-goods and that this demand shifts up in period T. Both features could be derived from alternative more complicated structures. The current formulation is adopted for tractability. ${ }^{17}$

\footnotetext{
${ }^{17}$ An alternative it to consider a T-production sector which uses N-goods as inputs, and which experiences a movement in the terms of trade or a productivity improvement in some future period. One could also extend the analysis to stochastic $d_{t}$, as long as there is an expected increase in the need for $\mathrm{N}$-goods. We do not pursue this here as we concentrate on sunspot uncertainty.
} 


\section{Managers}

$\mathrm{N}$-goods are produced with nontradables as the only input using a linear production technology

$$
q_{t+1}=\theta I_{t}
$$

These technologies are operated by successive cohorts of large numbers of managers. The reason for this setup is discussed in detail below. For the moment, it is convenient to think of a manager as a banker who lends to the $\mathrm{N}$ sector. A manager of the period $t$ cohort is a risk neutral agent who cares for consumption of tradables in period $t+1$ only. ${ }^{18}$ In period 0 , there is both a cohort of initial 'incumbent' managers who have an amount $q_{0}$ of nontradables to sell and a cohort of 'new' managers who have an endowment $e$ in terms of tradables.

\subsection{Institutions}

Our setup attempts to capture three institutional features of emerging economies. First, firms in the N-sector typically obtain funds through the banking system. ${ }^{19}$ Second, banks' creditors typically enjoy bailout guarantees, at least against systemic crises. ${ }^{20}$ Third, banks' lending is constrained by their capitalization and that of the firms they lend to. We do not model banks and firms separately. Instead, we introduce entrepreneurial nontradable producing firms, which we interpret as banks that specialize in lending to the nontradables sector. ${ }^{21}$ These firms face financing constraints and their creditors enjoy bailout guarantees.

\footnotetext{
${ }^{18}$ Managers incur a utility cost if they engage in 'diversion activities'. We will complete the description of their preferences below.

${ }^{19}$ See Saunders and Wilson (2000) for evidence on the nontradables exposure of Mexican banks.

${ }^{20}$ See Calomiris (1999) and Bordo and Schwartz (2000) for overviews of the frequency of recent bailout packages.

${ }^{21}$ Two comments are in order. First, Holmstrom and Tirole (1997) have explicitly modelled how a shock to the capital of the banking sector constrains lending and hence spills over to bank-dependent firms and constrains their investment. In our setting, this "credit chain" is subsumed in a single borrower-lender relationship. Second, note that the assumption that banks only lend to the N-sector is not restrictive. If one considered a setup where banks were able to lend to firms in both sectors, then in the presence of bailout guarantees banks would have incentives to choose a risky loan portfolio (i.e., they would choose to be 'excessively exposed' to the N-sector).
} 


\section{Financing-Constrained Firms}

It is a common theme in the literature that financing constraints arise if firms are run by insiders whose interests conflict with those of other claimholders. There is no single workhorse model of the dynamics of capital budgeting and capital structure choice that takes such conflicts of interest into account. One tractable formulation, which we employ here, is to think of a firm as being run by dynasties of myopic managers/entrepreneurs, who can divert funds to their own benefit, thereby creating a conflict of interest.

Each 'generation' consists of a continuum of firms of measure one. Since we will impose symmetry throughout, we state everything in terms of a representative firm. The manager in period $t$ begins with internal funds $w_{t}$. He raises an amount $b_{t}$ by issuing one-period bonds that pay off in T-goods, and an amount $b_{t}^{n}$ by issuing one-period bonds that pay off in N-goods. Since the promised interest rates on these bonds are $\rho_{t}$ and $\rho_{t}^{n}$, respectively, the total repayment promised by the entrepreneur is $p_{t+1}\left(1+\rho_{t}^{n}\right) b_{t}^{n}+\left(1+\rho_{t}\right) b_{t}{ }^{22}$

Since $b_{t}$ and $b_{t}^{n}$ are measured in T-goods, the budget constraint is

$$
p_{t} I_{t}+s_{t}+s_{t}^{n}=w_{t}+b_{t}+b_{t}^{n}
$$

where $s_{t}$ and $s_{t}^{n}$ are the amounts invested in international bonds that pay off in tradables and non-tradables, respectively. Here $I_{t}, b_{t}, b_{t}^{n}, s_{t}$ and $s_{t}^{n}$ must be non-negative. In the following period, a manager sells the output of $\mathrm{N}$-goods. He then pays out a fixed fraction $c$ of the profits as dividends to himself and passes on the remainder to the next manager. The goal of every manager is to maximize expected profits in the following period. ${ }^{23}$

\section{Enforceability of Contracts}

The financing decision is subject to two distortions: an enforceability problem and bailout guarantees. A firm is called insolvent if cash flow,

\footnotetext{
${ }^{22}$ The actual repayment may differ from the promised repayment. This is described below when we discuss the 'credit market game'.

${ }^{23}$ The advantage of the myopic manager setup is that we can analyze financial decisions period-by-period. Among other things, we do not have to take into account the effect of potential future rents on managers' decision to default strategically. This is especially useful in our setting, where financial decisions are interdependent due to the nature of bailout guarantees. Nevertheless, the main feature of the credit market, that borrowing depends on internal funds, would in general carry over to a dynamic firm problem (see, for example, Schneider (1999)).
} 
defined by

$$
\hat{\pi}\left(p_{t+1}\right):=p_{t+1} \theta I_{t}+(1+r) s_{t}+\left(1+r_{t}^{n}\right) p_{t+1} s_{t}^{n}-\left(1+\rho_{t}^{n}\right) p_{t+1} b_{t}^{n}-\left(1+\rho_{t}\right) b_{t}
$$

is negative. We will use the random variable $\zeta_{t+1}$ to indicate solvency. A solvent entrepreneur $\left(\zeta_{t+1}=1\right)$ can default strategically even though he would in principle be able to repay. We assume that he can divert all returns from investment to himself at time $t+1$, provided that he has incurred a non-pecuniary diversion cost $h\left[p_{t} I_{t}+s_{t}+s_{t}^{n}\right]$ at time $t$. In this case, lenders are left with nothing. 'Diversion' can be interpreted as an activity that reflects 'crony capitalism.'

In case of insolvency $\left(\zeta_{t+1}=0\right)$, the manager's payoff is zero. In addition, the gross returns from investment are dissipated in bargaining among the large number of creditors (so creditors also get a zero payoff). ${ }^{24}$ The fact that insolvent entrepreneurs cannot divert any returns corresponds to a certain amount of monitoring by lenders, or, with bailouts, of supervision by the bailout-granting institution. The idea is that insolvent firms are shut down quickly, before diversion activities can occur. ${ }^{25}$ This assumption essentially prevents managers from running a business that is insolvent in every state of nature, and financing it by issuing securities that are repaid by bailouts. This minimal amount of supervision appears reasonable.

The parameter $h$ can be interpreted as a measure of the severity of the enforceability problem. We would expect countries with lax contract enforcement, or industries with little collateral requirements to have relatively low values of $h$. If $h$ increases beyond $1+r:=\beta^{-1}$, it is always cheaper to repay debt rather than to divert, so that there is no enforceability problem. Since we are interested in firms that face financing constraints, we assume

\section{Assumption 1 (Financing Constraints)}

$$
\beta h<1
$$

\section{Bailout Guarantees}

\footnotetext{
${ }^{24}$ Assuming $100 \%$ bankruptcy costs is not necessary for the results. The role of bankruptcy costs is only to make insolvency undesirable in the absence of bailouts. Any (possibly small) positive percentage would be sufficient.

${ }^{25}$ In contrast, diversion in solvent firms cannot be detected until it is too late; it can only be prevented by providing incentives for managers ex ante not to set up a diversion scheme.
} 
In a bailout, lenders receive a fraction $F$ of the outstanding debts of all defaulting entrepreneurs, regardless of debt-denomination (N- or T-goods). The bailout policy is contingent on the number of defaults, in that the agency grants bailouts only if it faces a critical mass of defaults. For concreteness we assume that a bailout occurs if and only if more than $50 \%$ of firms default in a given period. The bailout is granted by an international organization. ${ }^{26}$

The contingent rule for bailouts captures the fact that bailouts typically occur when a large number of banks gets in trouble. ${ }^{27}$ It is also crucial for financing constraints to bite: if there was a basic 'deposit insurance' scheme (i.e. if a bailout was granted whenever a single entrepreneur defaulted), then guarantees would neutralize the enforceability problem.

This completes the description of the economy. We have considered a minimal setup in which we have assumed neither borrowing constraints nor risky debt denomination. Furthermore, since the production function is linear, the gradual character of the dynamics and the vulnerability to meltdowns that will emerge in equilibrium will derive from the interaction of the two distortions we emphasize in this paper.

\section{The Credit Market Game}

Since the occurrence of a bailout depends on how many firms default, their decisions are interdependent. The following simple 'credit market game' formalizes bond pricing with a large number of investors, while allowing for strategic interaction of bond issuers. The order of moves is as follows. At the beginning of period $t$ every new manager is assigned two risk-neutral lenders, one of whom invests in T-bonds only, while the other invests in N-bonds only. Given internal funds $w_{t}$ in terms of T-goods, all managers simultaneously

\footnotetext{
${ }^{26}$ It thus represents a 'windfall' gain for the country. Alternatively, one could assume that a lump sum tax is levied on consumers. Since consumers are not subject to wealth effects, this does not affect the rest of the equilibrium as long as their endowment is large enough. In a previous version of this paper we considered the case in which the bailout agency has limited reserves and the bailout rate is a decreasing function of the liabilitiesto-reserves ratio. Although the algebra is a bit more involved, the same qualitative results hold.

${ }^{27}$ The Mexican experience fits this assumption well. In the aftermath of the 1994 crisis, the entire financial system became insolvent. In order to ensure that all debt obligations were met, the US Treasury and international organizations provided Mexico a generous bailout. In 1999, however, a big Mexican firm, GAN, announced the suspension of the service of its debt (which stood at more than one billion US dollars). The Mexican government did not provide a bailout (The Wall Street Journal, June 16, 1999).
} 
announce an investment and borrowing strategy $\left(I_{t}, s_{t}, s_{t}^{n}, b_{t}, b_{t}^{n}, \rho_{t}, \rho_{t}^{n}\right)$ that satisfy their budget constraints (6). All lenders then simultaneously decide whether to fund the plan proposed to them (to purchase the bonds) or not. Subsequently, those managers whose plans have been funded decide whether or not to incur the diversion cost.

Payoffs to managers and lenders are determined in the following period. The (now old) managers sell their production of N-goods in exchange for T-goods. ${ }^{28}$ Those who have not incurred the diversion cost and are solvent, repay their debts. Their payoff is simply the remaining profit $\hat{\pi}\left(p_{t+1}\right)$. The payoff of solvent managers who have incurred the diversion cost equals the gross returns from their assets minus the diversion cost: $p_{t+1} \theta I_{t}+[1+r] s_{t}+$ $\left[1+r_{t}^{n}\right] p_{t+1} s_{t}^{n}-h\left[p_{t} I_{t}+s_{t}+s_{t}^{n}\right]$. Finally, insolvent managers receive a payoff of zero regardless of whether they incurred the diversion cost or not. Lenders receive the debt repayments of non-defaulting, non-diverting entrepreneurs. In the case that more than half of the entrepreneurs default, a bailout occurs. The lenders then receive a fraction $F$ of the outstanding debt, independently of what triggered the default.

In this game, the decision to incur the diversion cost is not affected by the plans of other managers. ${ }^{29}$ It follows that there is no diversion if and only if the expected repayment is less than the diversion cost:

$$
\left(1+\rho_{t}^{n}\right) E_{t}\left[\zeta_{t+1} p_{t+1}\right] b_{t}^{n}+\left(1+\rho_{t}\right) E_{t}\left[\zeta_{t+1}\right] b_{t} \leq h\left[p_{t} I_{t}+s_{t}+s_{t}^{n}\right]
$$

We will refer to this condition as the firm's borrowing constraint. This label is natural since we will show below that there cannot be an equilibrium in which managers divert. In fact (9) will be binding in all equilibria we consider. Importantly, we do not impose this borrowing constraint, but it arises endogenously as a result of the contract enforceability problem. In what follows we will use the random variable $\delta_{t}$ to indicate whether a managerial strategy entails diversion (i.e. $\delta_{t}=1$ if (9) holds).

\footnotetext{
${ }^{28}$ For completeness, managers whose plans are not funded receive a payoff of zero. This is not restrictive, since plans can involve no borrowing.

${ }^{29}$ The only interdependence between entrepreneurs is through the existence of bailouts and their effect on lenders' funding decisions. When the diversion decision is taken lenders have already put up their funds.
} 


\subsection{Equilibrium}

The following definition integrates the credit market game with the rest of the economy. A plan is a tuple $\left(I_{t}, s_{t}, s_{t}^{n}, b_{t}, b_{t}^{n}, \rho_{t}, \rho_{t}^{n}, \zeta_{t+1}, \delta_{t}\right)$, where we include the indicator variables for insolvency $\left(\zeta_{t+1}\right)$ and diversion $\left(\delta_{t}\right)$ along with the investment and borrowing strategy.

Definition 1 A symmetric equilibrium is a collection of stochastic processes $\left\{I_{t}, s_{t}, s_{t}^{n}, b_{t}, b_{t}^{n}, \rho_{t}, \rho_{t}^{n}, \zeta_{t}, \delta_{t}, p_{t}, w_{t}\right\}$ adapted to the filtration generated by $\left(\sigma_{t}\right)$ such that:

1. In every period $t$, given young entrepreneurs' wealth $w_{t}$, the current price $p_{t}$, and the conditional distribution of next period prices, the plan $\left(I_{t}, s_{t}, s_{t}^{n}, b_{t}, b_{t}^{n}, \rho_{t}, \rho_{t}^{n}, \zeta_{t+1}, \delta_{t}\right)$ is determined in a symmetric subgame perfect equilibrium of the credit market game.

2. The market for non-tradables clears

$$
\frac{d_{t}}{p_{t}}+I_{t}=\theta I_{t-1}
$$

3. Internal funds evolve according to $w_{0}=e_{0}$, and for $t \geq 1$ :

$$
w_{t}=\left\{\begin{array}{cc}
{[1-c] \hat{\pi}\left(p_{t}\right)} & \text { if } \delta_{t} \hat{\pi}\left(p_{t}\right)>0 \\
e & \text { otherwise }
\end{array}\right.
$$

The third part of the definition contains both the 'initial conditions' of the equilibrium and the evolution of internal funds. We assume that whenever there is default in a symmetric equilibrium, new managers in cohort $t$ receive an 'aid payment' $e$ to jump start their firms. ${ }^{30}$

In order to rationalize the facts mentioned in the Introduction it is essential that borrowing constraints arise in equilibrium, and that entrepreneurs find it profitable to invest in the production technology, and to issue T-debt. In order to determine the circumstance under which this occurs it is useful to classify plans according to whether they might lead to insolvency and/or

\footnotetext{
${ }^{30}$ This assumption is not essential to the results. As far as the existence of the equilibria we are interested in is concerned, we might as well assume that the $\mathrm{N}$-sector is shut down after a crisis. The aid payment could be part of a bailout package from abroad or be raised by lump-sum taxes.
} 
diversion of funds. We will refer to risky plans as those that keep the firm solvent in the good state, but lead to insolvency in the bad state $\left(\hat{\pi}\left(\bar{p}_{t+1}\right) \geq 0\right.$ $\left.>\hat{\pi}\left(\underline{p}_{t+1}\right)\right)$. In contrast, safe plans never lead to insolvency $\left(\hat{\pi}\left(\bar{p}_{t+1}\right) \geq 0\right.$, $\left.\hat{\pi}\left(\underline{p}_{t+1}\right) \geq 0\right)$. According to what plan is played in the symmetric equilibrium of the credit market game we will also refer to 'risky' and 'safe' equilibria.

Borrowing constraints arise only if plans that lead to diversion $\left(\delta_{t}=0\right)$ are dominated by plans that do not lead to diversion $\left(\delta_{t}=1\right)$. Furthermore, debt is denominated in tradables only if risky plans are preferred to safe plans.

\section{Investment and Debt Denomination}

In this section we discuss the investment and financing decisions of an individual firm at a given point in time. Readers who are only interested in the macroeconomic implications of these decisions can skip this section without loss of continuity. Current prices $(p)$ and expected future prices $(\bar{p}, \underline{p})$ are taken as given. In order for borrowing constraints to be binding in equilibrium and all debt to be denominated in T-goods there must be sufficient real exchange rate risk. As we shall see, returns must satisfy the following condition:

$$
\frac{\bar{p} \theta}{p}>1+r>h>\frac{p}{p}
$$

In this and the following section we will assume (12) holds. Then, in section 5 we will determine the circumstances under which it holds. The first inequality ensures that if crises are rare events ( $\alpha$ close or equal to one), investment in $\mathrm{N}$-goods is a positive NPV activity. This must clearly hold in any interesting equilibrium of the model. The third inequality says the crisis return is lower than the opportunity cost of diversion. It implies that firms will go bankrupt in a crisis state. Since in our model price risk is present if and only if bankruptcy risk is present, this must be true in any equilibrium in which $\alpha<1$. The second inequality follows from Assumption 1. In the next section we will derive the conditions under which (12) holds along the equilibrium path. 


\subsection{The Managerial Decision Problem}

Consider the interaction of a typical manager with his lenders. We have already discussed managers' diversion decision (see (9)). The funding decision of lenders takes the diversion behavior into account. For every firm, the assigned lenders will fund the plan proposed by the manager if the expected return (on their respective type of debt) is at least as large as the riskless interest rate.

$$
\begin{aligned}
\left(1+\rho_{t}\right) E_{t}\left[\delta_{t} \zeta_{t+1}+\left(1-\delta_{t} \zeta_{t+1}\right) \phi_{t+1}\right] & \geq 1+r, \\
\left(1+\rho_{t}^{n}\right) E_{t}\left[p_{t+1}\left(\delta_{t} \zeta_{t+1}+\left(1-\delta_{t} \zeta_{t+1}\right) \phi_{t+1}\right)\right] & \geq 1+r,
\end{aligned}
$$

This return depends on the behavior of other managers and lenders through bailout expectations, as summarized by the random variable $\phi_{t+1}$. Given our focus on symmetric 'safe' or 'risky' situations below, we will consider the following bailout expectations. In a risky situation, all firms pick a risky plan, all default in the low price state and a bailout occurs in that state. Thus, expectations in the risky case can be denoted by the random variable $\phi^{r}(F)$ that equals $F$ in the low price state and zero in the high price state. $F$ is the fraction of debt that is guaranteed if a majority of borrowers defaults. In a safe situation all firms will be always solvent. Thus, we simply set $F=0 .{ }^{31}$ To complete the characterization of firm behavior, we now solve the problem of selecting an optimal plan given prices and bailout expectations $\phi^{r}(F)$ :

Problem $\mathbf{P}(\mathbf{F})$. Given prices, choose a plan $\left(I, s^{n}, s, b^{n}, b, \rho^{n}, \rho, \delta, \zeta\right)$ that maximizes expected profit subject to the budget constraint (6) and the lenders' break-even constraints (13) with $\phi=\phi^{r}(F)$.

\footnotetext{
of what he was promised. Since the probability of a good state is $\alpha$, (13) becomes

$$
\begin{aligned}
\left(1+\rho_{t}\right)[\alpha+(1-\alpha) F] & \geq 1+r \\
\left(1+\rho_{t}^{n}\right)\left[\alpha \bar{p}_{t+1}+(1-\alpha) \underline{p}_{t+1} F\right] & \geq 1+r
\end{aligned}
$$
}

${ }^{31}$ To illustrate, consider the case of a risky plan that does not lead to diversion $\left(\delta_{t}=1\right)$. In the good state there is solvency $\left(\zeta_{t+1}=1\right)$, debt is repaid in full and there is no bailout. In the bad state there is bankruptcy $\left(\zeta_{t+1}=0\right)$ and each lender receives a proportion $F$ 
We refer to a plan that satisfies (13) given expectations $\phi_{t+1}$ as $\phi_{t+1^{-}}$ fundable. To solve $\mathrm{P}(\mathrm{F})$, we begin by deriving the best safe $\phi^{r}(F)$-fundable plan.

\section{2 'Safe' Investment and Financing}

The best safe plan maximizes profits subject to budget constraint (6), solvency constraints $\hat{\pi}(\bar{p}) \geq 0$ and $\hat{\pi}(\underline{p}) \geq 0$, and the lenders' break-even constraints (13), which in this case specialize to (37) and (44).

Lemma 2 (Best Safe Plans). For any bailout rate $F \geq 0$, and for $\alpha$ close to one, the firm's borrowing constraint binds at the best safe, fundable plan. There is no investment in riskless bonds and expenditure for physical investment is proportional to internal funds:

$$
p I=m^{s} w:=\frac{1}{1-\beta h} w
$$

Optimal debt denomination keeps the share of tradables debt below a threshold. In particular, it is always weakly optimal to denominate all debt in nontradables. The interest rates satisfy: $\rho=r$ and $1+\rho^{n}=[1+r] / p^{e}$.

If there is no exchange rate risk $(\alpha=1)$, Lemma 2 completely solves the managerial decision problem $\mathrm{P}(\mathrm{F})$. Firms run into a borrowing constraint because of the threat of diversion. This limits investment to a finite amount even though infinite investment would be preferred. Of course, as long as firms choose a safe plan, they do not enjoy a bailout subsidy. Here, the investment multiplier $m^{s}$ is independent of the bailout rate $F$.

It is always at least weakly cheaper to fund a safe plan with debt denominated in non-tradables because the set of fundable safe plans is restricted by the solvency constraint (the negation of (7)). For large levels of debt, the fact that this constraint is easier to satisfy if the debt payment is tied to the price of non-tradables may become relevant. Note that a strict preference for some fraction of debt denominated in non-tradables arises if $p \theta<h$.

More generally, Lemma 2 also characterizes the optimal plan if there is exchange rate risk and firms decide to fully hedge this risk. Of course, hedging itself might not be optimal. Instead, bailout guarantees might make gambling attractive to the manager. We thus examine next the best risky, $\phi^{r}(F)$-fundable plan. 


\subsection{Investment and Financing under Exchange Rate Risk}

The best risky, $\phi^{r}(F)$-fundable, plan maximizes profits subject to budget constraint (6), the lenders' break-even constraints (13) - which in this case specialize to (37) and (38) - and the constraints $\hat{\pi}(\bar{p}) \geq 0$ and $\hat{\pi}(p)<0$. These last constraints ensure that insolvency occurs in the bad state, but not in the good state.

\section{Lemma 3 (Best Risky Plans under Exchange Rate Risk)}

1. If $\alpha$ is close to one, the firm's borrowing constraint binds at the best risky, fundable plan. There is no investment in riskless bonds and expenditure in physical investment is proportional to internal funds:

$$
p I=m^{r} w=: \frac{1}{1-\beta h\left[1+\frac{1-\alpha}{\alpha} F\right]} w
$$

2. In the presence of bailout guarantees $(F>0)$, it is strictly optimal to denominate all debt in tradables. Interest rates satisfy $1+\rho=\frac{1+r}{\alpha+(1-\alpha) F}$ and $1+\rho^{n}=\frac{1+r}{\alpha \bar{p}+(1-\alpha) F \underline{p}}$.

This lemma makes three important points. First, it shows that bailout guarantees need not neutralize the effect of the enforceability problem. Under the condition on returns (12), lenders do not finance diversion plans. This gives rise (via (9)) to a borrowing constraint which, in turn, generates the familiar credit multiplier result: the amount of credit is proportional to the borrower's internal funds. Furthermore, if the production technology has positive NPV $\left(\frac{\bar{p} \theta}{p}>1+r\right)$, firms prefer investment to 'speculation' in bonds and the credit multiplier $m^{r}$ translates into an investment multiplier.

Lenders do not finance a diversion plan because bailout guarantees are 'systemic'. Since lenders have to guard against strategic default in the good state - where there is no bailout - a plan that leads to default in both states is acceptable to lenders only if they are promised a very high return in the bad state, where the guarantee applies. However, with debt, any promised returns for the bad state must be promised for the good state as well. When crises are unlikely ( $\alpha$ close to one) the promised payment has to tend to infinity. Clearly, this is unprofitable for the investor because it implies insolvency in the good state as well. 
Second, the amount of leverage that a firm can achieve with a risky strategy $\left(\frac{b}{w}=m^{r}-1\right)$ depends on how generous the bailout policy is. ${ }^{32}$ When an entrepreneur makes the diversion decision, he compares the diversion cost to the debt burden (principal plus interest) that can be avoided in the following period. In other words, the firm has a limited 'debt burden capacity'. Now, from the lender's break-even constraint, the more generous the bailout guarantee, the lower an interest rate can be promised while still keeping a plan fundable. In turn, a reduction in the interest rate lowers the debt burden, making room for more leverage. Here $\alpha^{-1}$ and $h$ work in the same direction as $F$. The easier it is to enforce contracts and the more likely are crises, the higher is the multiplier.

Third, undertaking risky plans goes hand in hand with a preference for T-debt. If there is enough exchange rate risk there will be bankruptcy in the bad state. Furthermore, if $F>0$, the bailout agency will pay part of the promise in the bad state. It is thus desirable for the firm to shift as much of the payment as possible into the bad state. This is achieved precisely by denominating all debt in tradables. Since lenders must break even, switching from non-tradable to tradable debt always shifts some of the debt burden from the good to the bad state, making the firm better off. ${ }^{33}$

We now put together the results on risky and safe plans to find the overall optimal plan. The main point is that a high enough bailout rate $F$ induces firms to select risky plans.

Proposition 4 (Optimal Investment and Financing under Exchange Rate Risk) Suppose crises are rare events ( $\alpha$ close to one).

1. If $F=1$, the optimal plan (i.e., the solution to the managerial decision problem $P(F)$ ) is the best risky fundable plan (characterized in Lemma 3).

2. If $F=0$, the optimal plan is the best safe fundable plan (characterized in Lemma 2).

\footnotetext{
${ }^{32}$ When $F=0$, the multiplier equals that in the safe case. If there are no bailout guarantees, the limit on leverage is independent of whether the chosen plan is risky or safe.

${ }^{33}$ Under a risky plan the expected repayments per unit debt are $\frac{\alpha[1+r]}{\alpha+(1-\alpha) F}$ for T-debt and $\frac{\alpha[1+r]}{\alpha+(1-\alpha) F \frac{\underline{\underline{p}}}{\bar{p}}}$ for N-debt. Since $\bar{p}>\underline{p}$, T-debt is strictly cheaper than N-debt for all $F>0$.
} 
To understand this result consider first the case of no guarantees $(F=0)$. We have already seen that, in this case, the limit on leverage is the same for risky and safe plans. If there were no bankruptcy costs, then we would have a 'Modigliani-Miller theorem for external finance': the limit on leverage would act like a technological bound on investment and the denomination of debt would be irrelevant. ${ }^{34}$ Bankruptcy costs induce a preference for N-debt. If a risky plan were undertaken, then revenues would be dissipated in the bad state. Thus, the total expected surplus to be divided between lenders and the entrepreneur is only $[\alpha \theta \bar{p}-(1+r) p] I^{s}+[1+r] w$. For a safe plan, the surplus is $\left[p^{e} \theta-(1+r) p\right] I^{r}+[1+r] w$. Since lenders always break even, the entrepreneur bears all bankruptcy costs in the form of higher interest rates. Also, there is no gain from choosing a risky plan because $I^{r}$ cannot be larger than $I^{s}$. Entrepreneurs are therefore always willing to avoid costly bankruptcy by denominating debt in non-tradables. ${ }^{35}$

What changes if bailout guarantees are in place (say $F=1$ )? There are two effects. First, if a risky plan is chosen, total expected surplus is increased by the bailout subsidy because the cost of capital is artificially lowered to $\alpha(1+r)$. The entrepreneur and the lenders now have $(\alpha \theta \bar{p}-\alpha(1+r) p) I^{r}+$ $\alpha(1+r) w$ to divide. The subsidy thus partly compensates for the deadweight costs of bankruptcy. Second, this effect is reinforced by the ability to have higher leverage and investment, which further increases the overall expected surplus. Proposition 4 shows that for sufficiently generous bailout guarantees, these two effects outweigh the bankruptcy costs and risky plans are preferred to safe plans.

\section{Risk Taking and Crises}

In the previous section we have described the behavior of an individual firm. In this section we discuss firms' equilibrium strategies as well as the determination of the real exchange rate within a period. In subsection 4.1, we continue to take exchange rate expectations as given. We ask how a cohort of managers as a whole invests and denominates debt under different scenarios. In particular, we show that under exchange rate variability and

\footnotetext{
${ }^{34}$ Of course, internal funds are not perfect substitutes for external finance because their availability would relax the investment constraint.

${ }^{35}$ This argument is similar to the derivation of a hedging demand in a costly state verification framework by Froot, Scharfstein and Stein (1993).
} 
generous bailout guarantees, risky debt denomination emerges in equilibrium, and generates widespread defaults in case of a devaluation. In subsection 4.2, we reverse the question: we take as given the denomination of debt, and look for equilibrium real exchange rates. Here we show that with high enough debt, multiple equilibria exist.

\subsection{Exchange rate risk and default risk}

We have seen in section 3 that if there are no bailout guarantees, managers hedge any real exchange rate risk perfectly by denominating debt in nontradables. Recall that bailouts are granted only during a 'systemic' crisis. Thus, as long as nobody expects a bailout, everybody hedges, and a crisis - and hence a bailout - cannot occur. In other words, a 'safe' equilibrium of the credit market game always exists. This is independent of whether the exchange rate is variable or not.

However, in a world with bailout guarantees this is not the only equilibrium. Indeed, suppose that a manager believes that all other managers will undertake risky plans. He will conclude that a bailout will occur in the bad state. Proposition 4 says that he will refrain from hedging and take on real exchange rate risk. He will in fact go bankrupt in the bad state, along with all the other managers, triggering a bailout. Formally, we have: ${ }^{36}$

Proposition 5 (Credit Market Equilibria) Suppose $\alpha$ is close to or equal to one.

1. There exists a safe symmetric equilibrium of the credit market game. In this equilibrium, a safe plan is funded and firms' borrowing constraints bind. Defaults and bailouts do not occur. Firms do not invest in bonds. Physical investment is $I=p^{-1} m^{s} w$. The total debt burden, in terms of tradables, during the following period is $L=h p^{\prime}\left[p^{e}\right]^{-1} m^{s} w$.

2. If $\alpha<1$, a risky symmetric equilibrium exists if and only if bailout guarantees are present $(F=1)$. In this equilibrium, a risky plan is funded and firms' borrowing constraints bind. All firms default in the

\footnotetext{
${ }^{36}$ Lemma 3 says that in the risky case there is indifference with respect to the debt denomination choice in the special case that $F=0$. We break ties by assuming that all debt is denominated in tradables. Similarly, in a safe equilibrium we break ties by denominating all debt in non-tradables. As Lemma 2 shows, this is weakly optimal
} 
bad state (where a bailout occurs), but not in the good state. Firms do not invest in bonds. Physical investment is $I=p^{-1} m^{r} w$. The total debt burden, in terms of tradables, during the following period is

$$
L=\alpha^{-1} h p I=\alpha^{-1} h m^{r} w .
$$

We conclude from this proposition that it is possible for exchange rate 'gambling' by managers to occur in equilibrium. Moreover, a period in which many managers gamble can be observed in an environment that previously saw no risk taking without any exogenous shift in policy or other fundamentals. It is enough that managers begin to believe that others will undertake risky actions. Through the nature of systemic bailout guarantees this can create shifts to a regime in which bailouts are exploited through risky actions which in turn make bailouts occur. A 'gambling regime' of this type will be inherently fragile for two reasons. First, a devaluation will lead to widespread defaults. From the point of view of this subsection, where the exchange rate is exogenous, this is a 'fundamental' reason. Second, it might be that managers' confidence in the propensity of others to gamble declines, in which case everybody becomes conservative and the economy switches again to a safe equilibrium. In what follows, we will typically be concerned with the first type of reversal. However, the move in the exchange rate will be endogenous and due to balance sheets effects, as we now explain.

\subsection{Twin Crises}

We now turn to the determination of the real exchange rate by characterizing a 'temporary equilibrium' for a typical period $t<T$. We assume that one of the equilibria from Proposition 5 was played in the previous period. The incumbent managers enter the current period with a supply of nontradables $q_{t}$, no bond holdings and a debt burden, $L_{t}+p_{t} L_{t}^{n} \cdot{ }^{37}$ The new cohort chooses its plans taking as given future prices and the value of the internal funds they get from incumbents' sales. Consumers' demand for non-tradables is equal to $d / p_{t}$.

As usual, investment of a borrowing constrained firm depends not only the rate of return, but also on cash flow. With our linear structure, the

\footnotetext{
${ }^{37} L_{t}\left(L_{t}^{n}\right)$ is the burden induced by T-debt(N-debt). From Proposition 5 we know that, if plans were in symmetric equilibrium last period, then managers will have exclusively one or the other. We use $L_{t}+p_{t} L_{t}^{n}$ because it is notationally convenient.
} 
rate of return enters only through the positive NPV condition (31): a high enough return is necessary for investment to be positive. If this is the case, investment expenditure will simply be proportional to internal funds. The size of the multiplier in period $t, m_{t}$, depends on whether safe $\left(m_{t}=m^{s}\right)$ or risky $\left(m_{t}=m^{r}\right)$ plans are undertaken: $p_{t} I_{t}=m_{t} w_{t}$.

As long as incumbents are solvent, internal funds are $w_{t}=(1-c) \hat{\pi}_{t}$, where $\hat{\pi}_{t}=p_{t} \theta I_{t}-L_{t}-p_{t} L_{t}^{n}$. In contrast, if the bad state is realized, firms become insolvent and the new cohort starts out with an endowment of $\mathrm{T}$ goods $e$. Investment expenditure is thus

$$
p_{t} I_{t}= \begin{cases}\eta_{t}\left[p_{t} q_{t}-L_{t}-p_{t} L_{t}^{n}\right] & \text { if } p_{t} q_{t} \geq L_{t}+p_{t} L_{t}^{n} \\ m_{t} e & \text { otherwise }\end{cases}
$$

where the cash flow multiplier $\eta_{t}$ is defined by $\eta_{t}:=(1-c) m_{t}$. It depends negatively on the 'dividend payout rate' $c$ (if profits are not reinvested, then balance sheet effects are weak) and positively on leverage (we have $\frac{b_{t}}{w_{t}}=$ $\left.m^{r}-1\right)$. High leverage is possible if the enforceability problem is not very severe (high diversion cost $h$ ) and if the probability of a crisis $(1-\alpha)$ is large. The latter effect arises because a larger probability of crisis increases the implicit subsidy from the bailout guarantee and hence increases debt capacity.

In a temporary equilibrium, the real exchange rate equalizes aggregate demand and the (predetermined) supply of nontradables: $D\left(p_{t}\right)=q_{t}$, where

$$
D\left(p_{t}\right)= \begin{cases}\frac{d}{p_{t}}+\eta_{t}\left[q_{t}-\frac{L_{t}}{p_{t}}-L_{t}^{n}\right] & \text { if } p_{t} q_{t}>L_{t}+p_{t} L_{t}^{n} \\ \frac{d+m_{t} e}{p_{t}} & \text { otherwise }\end{cases}
$$

Since supply is given, the key to having multiple equilibria is a backward bending aggregate demand curve. This is impossible if incumbent managers have only nontradables debt $\left(L_{t}=0\right)$. In this case, price changes lead to variations in both incumbents' revenues and their debt payments. In fact, incumbent profits (measured in nontradables) are completely insulated against price movements. This implies that, for solvent firms, investment demand from the N-sector is price inelastic. From the point of view of a manager in the new cohort, any increase in price (that might hurt investment demand) is matched by an increase in internal funds. Of course, this effect works both ways: a drop in the price that might encourage investment demand is always accompanied by an offsetting drop in internal funds. The upshot is that as 
long as incumbent plans satisfy $q_{t}>L_{t}^{n}$, demand slopes downward and there is a unique equilibrium price. From Proposition 5, the latter condition is always satisfied in a safe equilibrium.

However, multiple equilibria are possible if incumbents have T-debt on the books (and $L_{t}^{n}=0$ ). In this case price movements affect revenues, but keep the debt burden unchanged. It thus becomes important to distinguish between insolvent and solvent firms. For prices below the cutoff price $p_{t}^{c}=\frac{L_{t}}{q_{t}}$, all N-firms go bankrupt because revenues do not cover the debt burden. As a result, internal funds are only $e$. Total demand in this range is downward sloping. In contrast, for prices above $p_{t}^{c}$, an increase in the price is accompanied by a more than proportional increase in internal funds. The reason is that revenues increase while the debt burden remains the same. Equivalently, part of the debt burden measured in terms of nontradables is 'inflated away'. Consequently, investment demand is increasing in price.

It is apparent that if the balance sheet effect is strong enough to make aggregate demand 'bend backward', as in Figure 3, multiple market clearing prices, and hence self fulfilling 'twin crises' can exist. ${ }^{38}$ The strength of the balance sheet effect depends on two factors. Obviously, the liabilities of the old $\left(L_{t}\right)$ have to be large enough for them to matter. But it is also important that the investment capacity of the young be sufficiently sensitive to the liabilities of the old (i.e., that the cash flow multiplier $\eta$ be high). From (18), multiple market clearing prices arise if and only if

$$
L_{t}>d+m_{t} e \quad \text { and } \quad \eta_{t}>1
$$

With identical fundamentals, in terms of supply and debt, the market may clear in one of two equilibria. In a 'solvent' equilibrium (point B in Figure 3 ), the price is high, inflating away enough of firms' debt (measured in nontradables) to allow them to bid away a large share of output from consumers. In contrast, in the 'crisis' equilibrium of point A, the price is low to allow consumers and bankrupt firms with little internal funds to absorb the supply of nontradables.

Which of these two points is reached depends on expectations. Fundamentals determine only whether the environment is fragile enough to allow two equilibria. In view of (19), the relevant factors are a strong balance sheet

\footnotetext{
${ }^{38}$ More specifically, the balance sheet effect must outweigh the counteracting effect of consumption demand (which is downward sloping) and it must also make investment demand large enough relative to supply.
} 
effect and a high enough level of tradables debt. The former is facilitated by a low dividend payout rate and easy enforceability of contracts. The latter has been taken as given in this section.

In subsection 5.2 we will show that anticipated endogenous price risk can induce managers to take on enough T-debt for such risk to actually arise. For this to happen, bailout guarantees have to be generous. To carry out this analysis, however, we must turn to an explicitly dynamic analysis.

\section{$5 \quad$ Equilibrium Dynamics}

In this section we study the dynamic behavior of the economy. We begin in subsection 5.1 with an environment without bailout guarantees. We show that the existence of balance sheet effects together with growth expectations for the N-sector can lead to 'lending boom equilibria', characterized by fast growth of the N-sector, accumulation of debt and real appreciation. In subsection 5.2 we show how a lending boom can end in self-fulfilling twin crises, provided that bailout guarantees are present.

\subsection{Safe Lending Boom Equilibria}

We have seen in the previous section that, in the absence of bailout guarantees, managers will not be inclined to issue T-debt. In our model, the only source of uncertainty is the sunspot. Furthermore, multiple market clearing prices, which are crucial for a sunspot to matter, exist only if debt is denominated in tradables. It follows that, in the absence of bailout guarantees, there cannot be an equilibrium in which prices depend on the sunspot. Instead, in economies without bailout guarantees, equilibria must be 'safe': the 'safe' credit market equilibria of Proposition 5 are played every period and firms are always solvent.

Market clearing for nontradables requires that consumption and investment expenditure sum to the value of output: $d_{t}+m_{t} w_{t}=p_{t} q_{t}$. From Lemma 2 , we have that $m_{t}=m^{s}$. Thus, internal funds evolve according to

$$
\begin{aligned}
w_{t} & =(1-c)\left(p_{t} q_{t}-p_{t} L_{t}^{n}\right) \\
& =(1-c)\left(p_{t} q_{t}-h m^{s} w_{t-1}\right)
\end{aligned}
$$

Output is proportional to internal funds in the previous period: $q_{t}=\frac{\theta m^{s} w_{t-1}}{p_{t-1}}$. Combining these equations it follows that any equilibrium path of output and 
internal funds $\left(q_{t}, w_{t}\right)$ must be a solution to

$$
\begin{array}{rlrl}
q_{t} & =\theta \frac{m^{s} w_{t-1}}{m^{s} w_{t-1}+d} q_{t-1}, & & t \leq T \\
\frac{1-\eta^{s}}{1-c} w_{t} & =d-h m^{s} w_{t-1}, & & t<T \\
w_{T} & =\hat{d}-h m^{s} w_{T-1} &
\end{array}
$$

with initial conditions $q_{0}$ and $w_{0}=e_{0}$, and where $\eta^{s}=(1-c) m^{s}$ is the 'safe' cash flow multiplier. A solution to (20)-(22) is an equilibrium if the implied price path given by

$$
p_{t}=\left\{\begin{array}{cc}
\frac{d+m^{s} w_{t}}{q_{t}} & t<T \\
\frac{d}{q_{T}} & t=T
\end{array}\right.
$$

is steep enough to make the technology a positive NPV undertaking (i.e., $p_{t+1} \theta>(1+r) p_{t}$ for all $\left.t<T\right)$.

Equation (20) states that the fraction of nontradables production that is invested in every period depends on the financial strength of the N-sector. If internal funds are low, nontradables firms can borrow very little. Holding supply fixed, weak investment demand implies that the price is low and consumers absorb a larger fraction of supply. On the other hand, a strong $\mathrm{N}$-sector (high $w_{t}$ ) will try to expand and bid resources away from consumers. This increases the price.

Equation (21) provides a 'flow of funds' account for the 'consolidated' $\mathrm{N}$-sector, putting both cohorts of managers together. The right hand side is consolidated cash flow: sales to the household sector minus repayment of debt to foreigners. The left hand side may be called 'net new funds raised': it consists of new debt issued minus dividends paid out.

Whether consolidated cash flow is positive or negative in equilibrium now depends on the expansion strategy of the $\mathrm{N}$-sector, via the cash flow multiplier $\eta^{s}$. If $\eta^{s}<1$, the $\mathrm{N}$-sector makes a profit throughout. If the dividend payout rate $c$ is high enough, its size (measured, for example, by the value of investment $p_{t} I_{t}=m^{s} w_{t}$ ) gradually moves towards a steady state value. In this type of equilibrium, firms' behavior is independent of the preference shift occurring at date $T$. It would be the natural case to consider if we were interested in long run issues.

In contrast, if the dividend payout rate is low enough to allow the $\mathrm{N}$ sector to grow, the existence of 'growth expectations' for the N-sector allows 
another equilibrium. The N-sector can expand, in fact running a deficit over time, in anticipation of strong demand in the future. Since we are interested in characterizing the transition phase of an economy in the aftermath of reform, we focus on this second case. We thus assume that

\section{Assumption 2 (Expanding N-sector)}

$$
c<\beta h
$$

This assumption is necessary, but not sufficient to guarantee growth of the N-sector over time. First, it is apparent from the flow-of-funds equation (21) that the N-sector must be above a 'critical size' in period zero. If this is the case, debt and investment expenditure will rise over time as N-sector firms issue new debt to cover the sequence of deficits. Second, in the final period, the accumulated debt must be repaid. A lending boom equilibrium thus also requires a large enough preference shift at time $T$.

The previous discussion focused on the financial side of the N-sector and, implicitly, on the value of output $\left(p_{t} q_{t}\right)$. The technology parameter $\theta$ determines how this rise in value translates into changes in prices and quantities. If $\theta$ were very high, supply would outpace demand. As a result the price would fall over time, while investment would rise. At the other extreme, if $\theta$ were small, we could have an equilibrium along which nontradables become more and more scarce while firms would be chasing the returns offered by rising prices but could afford to invest less and less. To match the observations that $\mathrm{N}$-sector growth coincides with a real appreciation, we fix $\theta$ at an intermediate value.

\section{Assumption 3 (Technology Bounds)}

$$
\theta \in\left(1, \frac{\eta^{s} h}{\eta^{s}-1}\right)
$$

We are ready to establish the existence of lending boom safe equilibria.

Proposition 6 (Safe Equilibria) Suppose Assumptions 1 and 2 hold.

1. There is a region $E=\left\{\left(e_{0}, d\right): e_{0}>\underline{e}\right.$ and $\left.\hat{d}>\underline{d}\left(e_{0}\right)\right\}$ for the $N$-sector's initial funds and the demand parameter, such that for all economies with $\left(e_{0}, d\right) \in E$, a safe symmetric equilibrium exists in which debt and investment expenditure increase over time. 
2. If, in addition, Assumption 3 holds, then for large enough $T$ there is a $\tau<T$, such that $(i)$ the output of nontradables increases over time from $\tau$ on, and (ii) the real exchange rate appreciates between $\tau$ and $T-1$.

\subsection{Sunspot Equilibria}

We now consider an economy in which systemic bailout guarantees are present. The main point is that economies which would otherwise exhibit safe lending booms can now exhibit risky lending booms, which allow faster growth (financed by 'cheap' T-debt), but which may end in self-fulfilling twin crises. We begin with a preliminary question: the possibility of unanticipated self-fulfilling crises in the safe lending boom equilibria of Section 5.1. We then establish the existence of sunspot equilibria, in which the risky credit market equilibria of Section 4 are played during the boom.

\section{Safe Equilibria and Unanticipated Crises}

The safe lending boom equilibria derived in the previous subsection will continue to be equilibria in an economy with bailout guarantees. Suppose every manager believes that the safe equilibrium price will be realized for sure one period ahead. Since the existence of bailout guarantees is irrelevant, managers will simply play the best safe plan. As a result, the price evolves exactly as in a safe equilibrium.

To think about unanticipated crises, we use the fact that managers are indifferent between $\mathrm{T}$ and $\mathrm{N}$ debt if prices are deterministic (by Lemma 2 ). Suppose that debt is actually denominated in tradables. Unanticipated crises can now occur during sufficiently long safe lending booms. Indeed, we know from section 4 that multiple market clearing prices exist, provided the amount of T-debt to be repaid in period $t$ is large enough:

$$
h m^{s} w_{t-1}>d_{t}+m^{s} e
$$

We call a state $\left(q_{t-1}, w_{t-1}\right)$ fragile if $(26)$ holds. If the economy is in a fragile state, then outstanding debt is so large that it cannot be repaid by selling output only to consumers and new managers that start with $e$. It follows that there is a price which clears the market by defaulting all firms.

Fragility need not be present at all times in a safe lending boom equilibrium. In particular, if contract enforceability is not easy (low $h$ ), and $e$ is 
large relative to $e_{0}$, the initial phase of a boom $\left(w_{t-1}\right.$ close to $\left.e_{0}\right)$ need not be fragile. However, by Proposition 6, in any lending boom equilibrium the debt burden $L_{t}=h m^{s} w_{t-1}$ is increasing over time. The economy must thus enter into a 'fragile region' if the boom continues long enough. Of course, the economy cannot be in a fragile state in period $T-1$ : there can never be a crisis in the final period because firms do not reinvest.

\section{Anticipated Crises}

It is technically simple to focus on unanticipated crises, but it is conceptually unsatisfactory for several reasons. First, from Lemma 2, firms are indifferent between $\mathrm{T}$ and $\mathrm{N}$ debt in a safe equilibrium. We would thus be assuming fragility. Only if crises are anticipated can we rationalize this fragility as a result of risky debt denomination. Second, the economy with anticipated crises will behave differently while no crises occur: only if crises are anticipated can we make the point that growth is faster with bailout guarantees.

We are thus led to tackle the more difficult question of whether crises can actually occur with positive probability along the equilibrium path. We know from Section 4 that under exchange rate risk and bailout guarantees, managers may create credit risk from real exchange rate risk by financing investment with $\mathrm{T}$ debt. They will do so in particular if they expect $(i)$ a sufficiently high return on investment in the absence of a depreciation, $(i i)$ a sufficiently low return after a depreciation, so that it is possible to claim the bailout subsidy by defaulting; and (iii) a sufficiently low probability of a crisis, which ensures that the ex-ante expected return is high enough and borrowing constraints bind. Section 4 has also shown that if there is enough $\mathrm{T}$ debt, there are two market clearing prices, where the lower price bankrupts firms, and hence triggers a bailout. The question is whether these two effects can be elements of one consistent story.

Formally, can we construct an equilibrium price process, by making the sunspot variable $\sigma_{t}$ select among market clearing prices, such that the resulting return distribution encourages firms to issue enough $\mathrm{T}$ debt to validate the price process? In other words, we need to construct a set of beliefs about future prices that is consistent with a rationally anticipated self-fulfilling crisis. We thus need to find a range of probabilities $\alpha$ for the 'sunspot process', so that the sunspot 'matters' over a number of periods before the next to last one. 
Consider a typical period $t-1$. Suppose agents believe that there will be a crisis with probability $1-\alpha$ in period $t$, and that this risk induces them to issue T-debt. In the good state in period $t$, firms are solvent, and the transition is similar to the safe case:

$$
\begin{aligned}
\bar{w}_{t} & =(1-c)\left(\bar{p}_{t} q_{t}-L_{t}\right) \\
& =(1-c)\left(\bar{p}_{t} q_{t}-\alpha^{-1} h m^{r} w_{t-1}\right)
\end{aligned}
$$

Still conditioning on the good state, the market clearing and flow of funds equations are also essentially the same as in the safe case:

$$
\begin{aligned}
d+m^{r} \bar{w}_{t} & =\bar{p}_{t} q_{t} \\
q_{t} & =\frac{\theta m^{r} w_{t-1}}{p_{t-1}}
\end{aligned}
$$

It follows that for $\alpha$ close to 1, i.e. if crises are a relatively 'rare event', the evolution of the economy along the 'lucky path', along which no crisis occurs, is essentially the same as in the safe lending boom equilibria. Moreover, for $\alpha$ close to one, we have $p_{t}^{e} \approx \bar{p}_{t}$ and the expected return is close to the one that would prevail in a safe equilibrium with the same initial conditions. This suggests that there is a range of crisis probabilities, $(1-\alpha) \in(0,1-\bar{\alpha})$, for which internal funds increase over time and returns are sufficiently high to allow positive investment.

Condition (ii) is satisfied when firms go bankrupt in the bad state. If a crisis actually occurs in the bad state, internal funds of the new cohort are $\underline{w}_{t}=e$. The equilibrium price must be low enough to bankrupt the incumbent cohort $\left(\hat{\pi}\left(\underline{p}_{t}\right)<0\right)$ :

$$
\underline{p}_{t} q_{t}=d+m^{r} e<\alpha^{-1} h m^{r} w_{t-1}
$$

Clearly, for $\alpha$ close to one, this is implied by the condition for a fragile state (26). It follows that if the economy is in a fragile state in period $t-1$, a crisis can occur in period $t$ with conditional probability $1-\alpha$. It remains to characterize the third stage of the equilibrium path. Since the economy cannot be in a fragile state at $T-1$, there must be a switch to a safe path no latter than $T-2$. Clearly the demand shift at terminal time $T$ (i.e., $\hat{d}$ ) must be large enough to ensure that the N-sector can repay its accumulated deficits. We conclude that if the $N$-sector has enough time to grow, the 
sunspot can eventually matter and self-fulfilling crises can be anticipated. We now formally describe one particular sunspot equilibrium, which we will use below to interpret recent stylized facts about lending booms and crises.

Proposition 7 (Sunspot Equilibria) Suppose Assumptions 1-2 hold and lenders are fully bailed out $(F=1)$ in the event of a meltdown.

1. There exists a region

$S=\left\{\left(e_{0}, \alpha, T, d\right): e_{0}>\underline{e}, \alpha>\underline{\alpha}\left(e_{0}\right), T>\underline{T}\left(e_{0}, \alpha\right), \hat{d}>\underline{d}\left(e_{0}, \alpha, T\right)\right\}$

for the $N$-sector's initial funds, the probability of no crisis, the terminal time, and the demand parameter, such that for all economies with $\left(e_{0}, \alpha, T, \hat{d}\right) \in S$, a sunspot equilibrium exists.

2. In the equilibrium there is an interval $[\underline{\tau}, \bar{\tau}]$, with $\bar{\tau} \leq T-1$, during which a crisis occurs with conditional probability $1-\alpha$, provided that there has not been a crisis up to $t-1$. The probability of two crises in the interval $[0, T]$ is zero.

3. If, in addition, Assumption 3 holds, then there is a $\tau \in[\underline{\tau}, T)$ such that, along the 'lucky path' on which no crisis occurs, (i) the output of nontradables increases over time from $\tau$ on, and $(i i)$ the real exchange rate appreciates between $\tau$ and $T-1$.

4. If a crisis occurs at $t$, investment and credit are lower in $t$ than in $t-1$. The real exchange rate depreciates from $t-1$ to $t$. If $\underline{e}<e<\frac{d}{(\theta-1) m^{s}}$, output falls between $t$ and $t+1$.

It should be emphasized that the likelihood of self-fulfilling crises is not a free parameter. First, SE exist only if crises are relatively rare events. If the probability of a crisis was too high, low ex ante returns would discourage managers from investing in the first place. We take this feature of the model as a check of the plausibility of our particular sunspot story. Second, crises are more likely to happen toward the end of a boom, as the anticipated event that triggered the boom draws near. Note that even though prosperity is near for the N-sector, fragility and the size of a possible downturn become more severe. 


\subsection{Lending Booms and Speculative Crises}

In this subsection we relate the time series generated by the model to the stylized facts described in the Introduction. We also discuss what conditions make an economy vulnerable to crisis episodes.

\section{A complete boom-bust episode}

Figure 4 depicts the paths that an economy follows along risky and safe equilibria. Along the lucky path of a risky equilibrium credit and investment in the N-sector rise over time while the real exchange rate appreciates. At the same time, consumption actually falls. Here consumption should be interpreted broadly as "N goods not used by the N-sector". We thus have a drastic version of the transfer of resources that actually takes place during lending booms. In actual lending booms, we typically see the N-sector growing faster than the T-sector. This could presumably be recovered here if there was some common trend growth. A risky lending boom equilibrium features two key observed characteristics of credit: debt denomination is used to take on real exchange rate risk and leverage is unusually high. The benchmark in the model is the leverage achieved in a safe equilibrium (see Proposition 5). The lending boom develops gradually over time. The relevant 'adjustment costs' here are due to the contract enforceability problem. The N-sector can grow only gradually since it must wait for internal funds to accumulate.

A crisis occurs when the bad state of the sunspot is realized for the first time. A real depreciation and widespread bankruptcies in the N-sector result. This depletes the internal funds of the N-sector. Thus, its investment drops and can only gradually recover (due to the financial 'adjustment costs' mentioned above). At the same time, consumption actually jumps up. Again, this highlights the transfer of resources: the T-sector does not suffer a recession at all. A richer model, for example one that allows for some credit constraints in the T-sector, could take this theme further and generate a mild recession in the T-sector. In any event, the strength and duration of the recession goes in the right direction here.

\section{Who is to blame (1): guarantees and contract enforceability}

A key finding of this paper is that the interaction of contract enforceability problems and bailout guarantees creates the fragility required for selffulfilling crises. On the one hand, if there were no guarantees, firms would not be willing to take on price risk to claim a subsidy. Costly enforceability 
of contracts would still imply that the N-sector can grow only gradually and balance sheet effects would play a role during the lending boom. However, there would be no force that makes a boom end in a crisis. On the other hand, if there were only guarantees but no enforceability problems, then there would not be any balance sheet effects that make demand backward-bending, a necessary condition for a sunspot to matter.

There is an interesting nonlinearity in the relationship between the parameter $h$, which measures the contract enforceability problems, and the fragility of the economy. One the one hand, if the diversion cost is too large, risky equilibria do not exist. We have observed in Section 3 that, in this case, at the level of the individual firm, a credit constraint would not arise. Balance sheet effects are then absent and crises cannot occur. In other words, our crisis mechanism cannot work in countries with banking systems that are well integrated into international credit markets, because bank balance sheet effects are too weak. On the other hand, if $h$ is very small, Assumption 2 is not likely to hold. This precludes the existence of lending boom equilibria, whether safe or risky. Obviously, countries in which banks have very little access to international credit markets should not be expected to exhibit lending boom equilibria, and are therefore also immune to crises. The model thus predicts that countries at an intermediate level of integration will be most vulnerable.

Who is to blame (2): the role of liberalization and a rosy future

In our model, lending booms cannot occur in just any economy with bailout guarantees and enforceability problems. It is also necessary to have a future increase in the demand of the T-sector for nontradables. Otherwise the $\mathrm{N}$-sector would not be able to repay the accumulated deficits it runs during the lending boom. Backward induction then indicates that the sequence of returns that supports the lending boom would collapse. This suggests that the boom-bust episodes are more likely to occur during a transition period (following a far reaching reform or a natural resource discovery, for instance).

We would like to emphasize that good news about the future is not necessary for the 'crisis mechanism' that arises from the interaction of the two distortions. It could be activated in any environment where the banking sector has accumulated a sufficiently large debt burden. For example, this debt burden could be inherited from a formerly state-owned banking system in privatization. In our model, 'good news' about the future value of $\mathrm{N}$ goods, captured by the anticipated shift in preferences, are certainly a crucial ele- 
ment to produce a boom-bust episode which ends in a self-fulfilling crisis. We model this particular way of accumulating debt because it fits the Mexican experience well. However, we are not ready to conclude that it is a structural feature that is essential for creating fragility.

How likely is a crisis ?

Our model implies that even during a transitional period the likelihood of a self-fulling crisis is not a free parameter. If crises were not sufficiently rare events, either borrowing constraints would not arise, or would not be binding in equilibrium if they did arise. In either case, credit would not be constrained by internal funds and balance sheet effects would not exist in equilibrium. Clearly, if this was the case, crises could not occur.

If the probability of crises is not small enough, enforceability problems do not generate borrowing constraints - for the simple reason that a borrower could exploit the bailout agency by offering a very high interest rate (even though that would bankrupt him also in the good state!). Lenders do not care whether a borrower will go bankrupt in all states. The high expected bailout payments would merely allow lenders to break even, even if they received no payment in the no crisis state.

Suppose now that borrowing constraints are in place but that the crisis probability is not sufficiently low. Clearly, firms would be able to leverage a lot relative to current internal funds. Therefore, a lower real appreciation will be needed to deflate the inherited debt burden and to clear the nontradables market. A lower appreciation, in turn, reduces the expected return of investing in nontradables below the interest rate on bonds. As a result, firms will not invest and thus not borrow.

Pareto Optimal versus Equilibrium Nontradables' Production

To highlight the role of bailout guarantees, we compare safe and risky equilibria in the following result:

Corollary 8 (Effects of Bailout Guarantees) Consider two economies A and $B$ with parameters in $S$. The only difference between these economies is that $A$ has systemic bailout guarantees. Then, there is an SE where $A$ and $B$ behave identically up to time $\underline{\tau}-2$, after which the $N$-sector in economy A grows faster and exhibits higher leverage along the lucky path, as long as a crisis does not occur. However, A experiences a crisis and subsequent recession with positive probability while $B$ does not. 
This Corollary implies that systemic bailout guarantees might induce faster economic growth by easing borrowing constraints. Thus, it is not obvious that eliminating them is desirable under all circumstances. To illustrate this point, it is useful to characterize the set of Pareto optima. The allocation problem that has to be solved in our economy is $(i)$ to distribute the available endowment of tradables among consumers and managers and (ii) to efficiently accumulate nontradables to equate the marginal rates of substitution and transformation: $\frac{d_{t}}{v_{t}}=\beta \theta \frac{d_{t+1}}{v_{t+1}}$. It follows that the Pareto optimal production of $\mathrm{N}$-goods can be characterized by the following law of motion: ${ }^{39}$

$$
q_{t}=\left(1-\frac{1-\beta}{1+\beta^{T-t}\left(\frac{\hat{d}(1-\beta)}{d}-1\right)}\right) \theta q_{t-1} ; \quad t=1, \ldots, T
$$

The fraction of output that should be devoted to investment is thus increasing over time, and depends positively on the anticipated preference shift $\frac{\hat{d}}{d}$. Comparing (30) and (20), there is no reason that the use of nontradables in a no-bailout regime should be Pareto optimal. Investment could be too large or too small, depending on the financial position of the N-sector. In fact, if the future looks sufficiently brighter than the present, the presence of bailout guarantees might bring the path of N-goods output nearer to the Pareto optimal path, as shown in Figure 4. This is because bailout guarantees might induce a faster growth rate of output (see (20) and (28)).

\section{Conclusions}

In the late 1980s several countries implemented far reaching reforms that reduced the size of the government sector and promoted the rapid growth of the private sector. These reforms were associated with large increases in bank lending to the private sector. As a result, the well-known balance of payments (BoP) crises associated with fiscal and monetary imbalances were superseded by 'new' boom-bust cycles in which bank lending, foreign exchange debt, and bailout guarantees took center stage. In these episodes the build-up phase

\footnotetext{
${ }^{39}$ The key here is that only nontradables are used to produce nontradables, and only the consumer enjoys nontradables. This means that the Pareto optimal law of motion for nontradables can be derived independently of managerial preferences and welfare weights of different agents.
} 
has been characterized by a real exchange rate appreciation and a lending boom. During these booms, credit grows unusually fast and firms denominate their debt mainly in foreign currency. This is particularly risky for firms in the non-tradeable sector because they become vulnerable to sudden real depreciations. Foreign currency debt might be risky, but interest rates are 'dirt cheap' and banks are more than willing to make foreign currency loans: after all, the principle that 'heads I win, tails you lose' reigns.

This creates a problem for the economy as a whole. When a policy correction is attempted, or a negative rumor hits, the needed improvement in the current account is accompanied by wide-spread bankruptcies and a massive real depreciation. As some Mexican officials were quoted, when referring to Mexico before the 1994 crisis, "there is no such thing as a $10 \%$ depreciation." In the aftermath of the crisis there is a credit crunch that hits the nontradable sector especially hard. This sector experiences a protracted recession, but once firms' financial wealth recuperates the boom starts all over again.

In this paper we have shown that these boom-bust episodes can be generated from the interaction between two distortions that are particularly acute in emerging markets: systemic bailout guarantees and low enforceability of financial contracts.

Is there a sense in which systemic bailout guarantees are ex-ante socially desirable? Suppose that after a transition period following trade reform, or after an oil discovery, a positive shift in the demand for nontradables by the export sector is expected. Since guarantees provide an implicit subsidy (that might loosen the borrowing constraints faced especially by the nontradables sector), they might bring the allocation of resources between tradables and nontradables production nearer to a Pareto optimal allocation. However, this comes at a 'cost'. Since guarantees are systemic, not idiosyncratic, the implicit subsidy can only be cashed-in if there is a systemic meltdown. In the absence of exogenous shocks, this can only occur if the nontradables sector borrows in foreign currency so that self-fulfilling real depreciations are possible. Since these crises are followed by credit crunches, it would seem as though there are indeed no free lunches.

Interestingly enough, our results have been obtained in a non-monetary model. This suggests that boom-bust cycles might exist under quite different exchange rate regimes and/or monetary policy rules. It might well be the case, for example, that a specific monetary regime blocks certain transmission mechanisms. However, this does not mean that the candidate monetary regime has gotten rid of the boom-bust cycle: the cycle might simply appear 
under a different guise.

In future work we plan to investigate how different aspects of exchange rate regimes influence the transmission mechanisms we have identified in this paper. This work will be helpful in evaluating the factors that make economies vulnerable to crises, and in thinking about policy measures to prevent and respond to crises.

\section{Appendix}

In the results of Section 3 we have let $\alpha$ go to one for given prices. We feel that this improves the exposition of the static case. Since in the results of Section 5 we cannot let $\alpha$ go to one, we will restate the static results for $\alpha \neq 1$ in a series of Lemmas marked with an asterisk. The Lemmas in the text follow from the next, obvious fact, and the Lemmas we prove below.

Lemma 9 If the return condition (12) is satisfied and $\alpha$ is sufficiently close to one, the following conditions hold under any bailout policy F:

1. (Positive net present value)

$$
p^{e} \theta \geq(1+r) p
$$

2. (Default in Low Price State)

$$
\stackrel{p}{\underline{p}} \theta<\alpha^{-1} h
$$

3. (Bound on High Price State)

$$
\alpha^{-1} h>(1-\alpha) \frac{\bar{p}}{p} \theta
$$

4. (Crises are Rare Events)

$$
\alpha>\max \{\beta h, 1-\beta h\}
$$

5. (Positive Net Return in the High Price State)

$$
\frac{\bar{p}}{p} \theta \geq \frac{1+r}{\alpha+(1-\alpha) F}
$$


In what follows we will denote by $\Pi_{t+1}^{r, d}\left(\Pi_{t+1}^{r, n d}\right)$ the expected payoff of a risky plan that leads to diversion (no-diversion). For safe plans we use analogous notation replacing the superscript $r$ by $s$ :

$$
\begin{array}{ll}
\Pi_{t+1}^{r, n d}=\alpha \hat{\pi}\left(\bar{p}_{t+1}\right), & \Pi_{t+1}^{s, n d}=\alpha \hat{\pi}\left(\bar{p}_{t+1}\right)+[1-\alpha] \widehat{\pi}\left(\underline{p}_{t+1}\right), \\
\Pi_{t+1}^{r, d}=\alpha \bar{\Delta}\left(\bar{p}_{t+1}\right), & \Pi_{t+1}^{s, d}=\alpha \bar{\Delta}\left(\bar{p}_{t+1}\right)+[1-\alpha] \underline{\Delta}\left(\underline{p}_{t+1}\right),
\end{array}
$$

where $\hat{\pi}\left(p_{t+1}\right)$ is defined in (7), and

$$
\begin{aligned}
& \bar{\Delta}\left(\bar{p}_{t+1}\right):=\bar{p}_{t+1} \theta I_{t}+[1+r] s_{t}+\left[1+r_{t}^{n} \bar{p}_{t+1} s_{t}^{n}-\alpha^{-1} h\left[p_{t} I_{t}+s_{t}+s_{t}^{n}\right],\right. \\
& \Delta\left(\underline{p}_{t+1}\right):=\underline{p}_{t+1} \theta I_{t}+[1+r] s_{t}+\left[1+r_{t}^{n}\right] \underline{p}_{t+1} s_{t}^{n} .
\end{aligned}
$$

Proof of Lemma 2. The following Lemma and Lemma 9 directly imply Lemma 2.

Lemma $2^{*}$. If conditions (31) and (33) hold, then the implications of Lemma 2 are true.

Proof. The best safe fundable plan $\left(I, s, s^{n}, b, b^{n}, \rho, \rho^{n}\right)$ that does not lead to diversion maximizes

$$
\begin{aligned}
\Pi^{s, n d}= & \alpha\left(\bar{p} \theta I+(1+r) s+(1+r) \bar{p}\left(p^{e}\right)^{-1} s^{n}-(1+\rho) b-\left(1+\rho^{n}\right) \bar{p} b^{n}\right)+ \\
& (1-\alpha)\left(\underline{p} \theta I+(1+r) s+(1+r) \underline{p}\left(p^{e}\right)^{-1} s^{n}-(1+\rho) b-\left(1+\rho^{n}\right) \underline{p} b^{n}\right)
\end{aligned}
$$

subject to the budget constraint (6), the borrowing constraint

$$
\left(1+\rho^{n}\right) p^{e} b_{t}^{n}+(1+\rho) b_{t} \leq h\left[p_{t} I_{t}+s_{t}+s_{t}^{n}\right]
$$

the solvency constraints $\hat{\pi}(\bar{p}) \geqslant 0, \hat{\pi}(\underline{p}) \geq 0$, and the lenders' break-even constraints

$$
1+\rho_{t} \geq 1+r, \quad\left(1+\rho_{t}^{n}\right) p_{t}^{e} \geq 1+r .
$$

It is clearly optimal to set $\rho=r$ and $1+\rho^{n}=\frac{1+r}{p^{e}}$. Condition (31) implies that $s^{n}>0$ cannot be optimal, since N-bonds are dominated in rate of return by investment. Similarly, we cannot have $\theta I<\left(1+\rho^{n}\right) b^{n}$ at the optimum. If this was the case, both $I$ and $b^{n}$ could be reduced, strictly increasing profits and relaxing all constraints. But if $\theta I \geq\left(1+\rho^{n}\right) b^{n}$, the solvency constraint for the high price state is implied by that for the low price state, which is given by:

$$
\underline{p} \theta I+(1+r) s+(1+r) \underline{p}\left(p^{e}\right)^{-1} s^{n}-(1+\rho) b-\left(1+\rho^{n}\right) \underline{p} b^{n} \geq 0
$$


It then follows that $b=0$ is optimal: the two types of debt and the two types of storage are exchangeable in the objective and in all constraints except for the low price state solvency constraint, where T-debt is more expensive. It is thus weakly better to replace all $b$ with $b^{n}$. We can now reformulate the problem as choosing $\left(I, s, b^{n}\right)$ to maximize $\left(\frac{p^{e} \theta}{p}-(1+r)\right) p I+(1+r) w$, subject to the borrowing and solvency constraints

$$
\left(1-\frac{h}{1+r}\right)(p I+s) \leq w, \quad\left(1-\frac{p^{e} \theta}{p(1+r)}\right) p I+\left(1-\frac{p^{e}}{\underline{p}}\right) s \leq w .
$$

Since $p^{e} \theta \geq(1+r) p$ (by (31)), the solvency constraint is irrelevant and optimal investment is $p I=\frac{w}{1-\beta h}$. This yields a payoff equal to $\bar{\Pi}^{s, n d}=$ $\frac{p^{e} \theta p^{-1}-h}{1-\beta h} w$.

We now show that the best safe, fundable plan that leads to diversion cannot yield a profit higher than $\bar{\Pi}^{s, n d}$. This plan maximizes profits subject to the requirement that the borrowing constraint (9) not hold, and $\hat{\pi}(\bar{p}), \hat{\pi}(\underline{p}) \geq$ 0 . Since we just want to bound the payoff, we ignore the borrowing constraint (imposing it cannot increase payoffs). We then know that the interest rates should be set as low as possible to relax the solvency constraints, which can now be written as

$$
\begin{aligned}
& \hat{\pi}(\bar{p})=\bar{p} \theta I+(1+r) s+(1+r) \bar{p}\left(p^{e}\right)^{-1} s^{n}-\frac{1+r}{(1-\alpha) \phi} b-\frac{1+r}{(1-\alpha) \phi} \frac{\bar{p}}{p} b^{n} \geq 0, \\
& \hat{\pi}(\underline{p})=\underline{p} \theta I+(1+r) s+(1+r) \underline{p}\left(p^{e}\right)^{-1} s^{n}-\frac{1+r}{(1-\alpha) \phi} b-\frac{1+r}{(1-\alpha) \phi} b^{n} \geq 0,
\end{aligned}
$$

Without loss of generality, we can assume $b^{n}=0$. Moreover, the constraint for the bad state implies the one for the good state. We thus reformulate the problem as maximizing $\left(p^{e} p^{-1} \theta-h\right) p I+(1+r-h) s+(1+r-h) s^{n}$ subject to

$$
\left(1-\beta \underline{p} p^{-1} \theta(1-\alpha) \phi\right) p I+(1-(1-\alpha) \phi) s+\left(1-\underline{p}\left(p^{e}\right)^{-1}(1-\alpha) \phi\right) s^{n} \leq w .
$$

The shadow costs multiplying the portfolio choices in the constraint are positive. For the shadow cost of investment, this follows from (33), and it is obvious for T-bonds. In addition, (31) implies that the shadow cost of Nbonds is higher than that of investment and so the former must be positive also. 
Since investment has a higher marginal benefit (but a possibly higher shadow cost than T-bonds), it is not clear what the preferred instrument is. We can concentrate on plans that satisfy the constraint with equality and bound the payoff by showing that for both the plan with $I=s^{n}=0$ and that with $s^{n}=s=0$, the payoff is lower than $\bar{\Pi}^{s, n d}$. For the former plan we have $\bar{\Pi}^{s, d} \leq \frac{1+r-h}{1-(1-\alpha) \phi} w<(1+r) w \leq \bar{\Pi}^{s, n d}$. The second inequality uses the fact that $\alpha>1-\beta h$ and the third inequality follows because setting $s=w$ is a fundable safe plan. For the plan with $s^{n}=s=0$ we have $\bar{\Pi}^{s, d} \leq \frac{p^{e} p^{-1} \theta-h}{1-\beta p p^{-1} \theta(1-\alpha) \phi} w$, which is less than $\bar{\Pi}^{s, n d}$ by (33). Finally, we consider the optimal debt policy. We already know that any plan with $b^{n}=I-w$ $(\gamma=0)$ is optimal. The remaining question is whether there are other plans with $b>0$ and $b+b^{n}=I-w$. We need only check whether these plans satisfy the solvency constraint

$$
\underline{p} \theta-(1+r) \gamma(I-w)-\underline{p} \frac{1+r}{p^{e}}(1-\gamma)(I-w) \geq 0
$$

This is equivalent to

$$
\gamma<\bar{\gamma}=\min \left\{\left(\frac{p^{e}}{p} \theta-h\right)\left(\frac{p^{e}}{p} \frac{h}{\underline{p}}-h\right)^{-1}, 1\right\}
$$

Proof of Lemma 3. The following Lemma and Lemma 9 directly imply Lemma 3.

Lemma $3^{*}$. Suppose $\alpha<1$. If conditions (31)-(34) hold, then

1. If (35) holds, the best risky plan is a no diversion plan. Expenditure for physical investment is given by (15) and, with $s=s^{n}=0$.

2. If (35) does not hold, the profit from risky plans is bounded above by $(1+r) w$.

3. If (35) holds and bailout guarantees are present $(F>0)$, all debt is denominated in tradables.

\section{Proof.}

Parts 1 and 2. As a first step, we determine the best risky fundable plan that does not lead to diversion. In the second step we will show that the best risky fundable plan with diversion is less profitable. 
Step 1. The best risky fundable plan with no diversion maximizes $\alpha \hat{\pi}\left(\bar{p}_{t+1}\right)$ subject to budget constraint (6), borrowing constraint (9), a version of the lenders' break-even constraint (13), given by

$$
(1+\rho)(\alpha+(1-\alpha) F) \geq 1+r, \quad\left(1+\rho^{n}\right)(\alpha \bar{p}+(1-\alpha) F \underline{p}) \geq 1+r
$$

as well as

$$
\begin{aligned}
& \hat{\pi}(\bar{p})=\bar{p} \theta I+(1+r) s+(1+r) \bar{p}\left(p^{e}\right)^{-1} s^{n}-(1+\rho) b-\left(1+\rho^{n}\right) \bar{p} b^{n} \geq 0 \\
& \hat{\pi}(\underline{p})=\underline{p} \theta I+(1+r) s+(1+r) \underline{p}\left(p^{e}\right)^{-1} s^{n}-(1+\rho) b-\left(1+\rho^{n}\right) \underline{p} b^{n}<0
\end{aligned}
$$

Without loss of generality, the break-even constraints can be taken to be binding. Suppose one of them was slack at the optimal plan. We could then reduce the interest rate: profits are not decreased (they go up if debt is positive) and all constraints would still hold. Interest rates are thus

$$
1+\rho^{n}=\frac{1+r}{\alpha \bar{p}+(1-\alpha) F \underline{p}}, \quad 1+\rho=\frac{1+r}{\alpha+(1-\alpha) F}
$$

We first show that $b^{n}>0$ cannot be optimal. For any policy involving $b^{n}>0$, we can construct an alternative policy by increasing $b$ slightly and decreasing $b^{n}$ by the same amount. Since $\left[1+\rho^{n}\right] p<1+\rho<\left[1+\rho^{n}\right] \bar{p}$, the alternative policy must yield higher expected profits and still satisfy all the constraints. Note also that the profit is strictly increased if $F>0$. Therefore, $F>0$ implies $b^{n}=0$.

A risky plan with $s>0$ can never be optimal. Suppose to the contrary that $s>0$ is optimal. Then we can reduce slightly $s$ and $b$ by the same amount, strictly increasing the expected payoff (note that $b>0$ must hold at the initial plan by the insolvency constraint). This leads to strictly higher profits (since $\rho>r$ ). The borrowing constraint is unaffected. The insolvency constraint still holds if the change is small enough, since it held with strict inequality at the original plan. This is a contradiction.

Setting $b^{n}=s=0$ we can reformulate the problem as that of choosing $\left(I, s^{n}\right)$ to maximize

$$
\alpha\left(\frac{\bar{p} \theta}{p}-(1+\rho)\right) p I+\alpha\left(\frac{\bar{p}(1+r)}{p^{e}}-(1+\rho)\right) s^{n}+\alpha(1+\rho) w
$$


subject to the borrowing and insolvency constraints

$$
\begin{array}{r}
\left(1-\frac{1}{\alpha(1+\rho)} h\right)\left(p I+s^{n}\right) \leq w, \\
\left(1-\frac{\underline{p \theta}}{p(1+\rho)}\right) p I+\left(1-\frac{\underline{p}(1+r)}{p^{e}(1+\rho)}\right) s^{n}>w .
\end{array}
$$

By (31), the net return on physical investment in the objective is higher for funds invested in the technology than for investment in $\mathbf{N}$-bonds. In addition, by (34), (42) imposes an upper bound on total funds invested.

Suppose that (35) does not hold. Then the net return on both investment opportunities is negative. It follows that there does not exist a best risky no diversion plan and that the profit from all risky plans is bounded above by $(1+r) w$. Otherwise, if (35) holds, the investment expenditure that maximizes (41) subject (42) only is $p I=\frac{w}{1-\frac{1}{\alpha(1+\rho)} h}=\frac{w}{1-\beta h\left(1+\frac{1-\alpha}{\alpha} F\right)}$. Finally, (32) implies that this solution also satisfies the second constraint. We have found the optimal no diversion plan under (35). The expected payoff under this plan is

$$
\bar{\Pi}^{r, n d}=\frac{\alpha \theta \bar{p} p^{-1}-h}{1-\frac{h}{\alpha(1+\rho)}} \cdot w
$$

Step 2. Consider now the best risky fundable diversion plan. Such plans maximize $\Pi^{r, d}=\alpha\left[\bar{p} \theta I+(1+r) s+\left(1+r^{n}\right) \bar{p} s^{n}\right]-h\left(p I+s+s^{n}\right)$ subject to budget constraint (6), the break-even constraints,

$$
(1-\alpha) \phi_{t+1}\left(1+\rho_{t}\right) \geq 1+r, \quad(1-\alpha) \phi_{t+1}\left(1+\rho_{t}^{n}\right) \underline{p}_{t+1} \geq 1+r .
$$

the riskiness requirement (39)-(40), and the requirement that borrowing constraint (42) does not hold. The debt choices enter only through the solvency and budget constraints. By a similar argument to that above, we can set $b^{n}=0$ without loss of generality. Our goal is to bound the payoff under a diversion plan. We thus ignore (9) and (40). Imposing them will, if anything, make this payoff even lower. It is then optimal to set the interest rate as low as possible and to use the break-even constraint for T-debt holding with equality. We solve the problem of choosing $\left(I, s, s^{n}\right)$ to maximize

$$
\left[\alpha \bar{p} p^{-1} \theta-h\right] p I+[\alpha(1+r)-h] s+\left[\alpha(1+r) \bar{p}\left(p^{e}\right)^{-1}-h\right] s^{n}
$$


subject to (6), (44) and the insolvency constraint:

$$
\left(1-\beta \bar{p} p^{-1} \theta(1-\alpha) F\right) p I+(1-(1-\alpha) F) s+\left(1-\bar{p}\left(p^{e}\right)^{-1}(1-\alpha) F\right) s^{n} \leq w .
$$

This problem has a solution because the three terms (shadow costs) multiplying the portfolio choices in the constraint are positive. For the shadow cost of investment, this follows from (33), $\alpha>\beta h$ and $F<1$. It follows trivially for T-bonds. Finally, (31) implies that the shadow cost of N-bonds is higher than that of investment, so that this shadow cost must be positive also.

By (31), the marginal benefit of investment is higher than that of either type of bond, and the shadow cost of investment is lower than that of Tbonds. The best plan must thus involve as much investment as possible, such that the insolvency constraint binds. This yields an upper bound on the payoff of

$$
\bar{\Pi}^{r, d} \leq \frac{\alpha \theta \bar{p} p^{-1}-h}{1-\beta \bar{p} p^{-1} \theta(1-\alpha) F} \cdot w
$$

On the one hand, if (35) does not hold, then $\bar{\Pi}^{r, d}<(1+r) w$. On the other hand, if (35) holds, then a best risky no diversion plan exists and (33) implies $\bar{\Pi}^{r, d}<\bar{\Pi}^{r, n d}$.

Part 3. Consider the optimal debt policy. We have already shown in Step 1 that under the optimal non-diversion plan it is strictly optimal to have $b^{n}=0$ if $F>0$. Since the optimal non-diversion plan is the overall optimal plan, this proves Part 3.

Proof of Proposition 4. The following proposition and Lemma 9 directly imply Proposition 4.

Proposition $4^{*}$. If conditions (31)-(34) hold, then the implications of Lemma 4 are true.

Proof. If $\alpha=1$, then the concept of a risky plan is not defined. It follows that the best safe plan is the optimal plan.

Suppose instead that $\alpha<1$. Consider first the case $F=0$. If (35) does not hold, then the optimal plan cannot be a risky plan, since, by Lemma $3^{*}$, the best risky plan yields less than $(1+r) w$. If (35) does hold, we know from Lemmas $2^{*}$ and $3^{*}$ that a best safe plan and a best risky plan exist. From the proofs of these lemmas, profits are $\Pi^{s}:=\frac{p^{e} \theta p^{-1}-h}{1-\beta h} w$ and $\Pi^{r}=\frac{\alpha \bar{p} \theta p^{-1}-h}{1-\beta h\left(1+\frac{1-\alpha}{\alpha} F\right)} w$, respectively. It is clear that a safe plan is preferred if $F=0$. 
For $F=1,(35)$ is implied by (31). Hence, both a best safe plan and a best risky plan exist. Using the definition of $p^{e}$, we obtain after some algebra that $\Pi^{r}>\Pi^{s}$ if and only if

$$
\underline{p} \theta p^{-1}<\alpha^{-1} h \frac{p^{e} \theta p^{-1}-h}{1+r-h}
$$

We know that $p \theta p^{-1}<\alpha^{-1} h$ by (32), and the fraction on the right hand side is greater than one, by (31).

We have shown that a safe plan dominates if $F=0$ or $\alpha=1$, while a risky plan dominates if $\alpha<1$ and $F=1$. The only task left is to rule out plans that are neither safe nor risky. Plans that lead to insolvency in both states yield zero profit and are obviously inferior. Consider a plan that leads to solvency in the bad state and insolvency in the good state. For such a plan, positive profits accrue only in the low price state and it satisfies at least the budget constraint and

$$
\begin{aligned}
& \hat{\pi}(\bar{p})=\bar{p} \theta I+(1+r) s+(1+r) \bar{p}\left(p^{e}\right)^{-1} s^{n}-(1+\rho) b-\left(1+\rho^{n}\right) \bar{p} b^{n}<0, \\
& \hat{\pi}(\underline{p})=\underline{p} \theta I+(1+r) s+(1+r) \underline{p}\left(p^{e}\right)^{-1} s^{n}-(1+\rho) b-\left(1+\rho^{n}\right) \underline{p} b^{n} \geq 0,
\end{aligned}
$$

Since we want to bound the payoff, we ignore constraints related to diversion. It cannot be optimal to have either $I, s^{n}$ or $b$ positive (since investment and N-bonds are dominated by T-bonds in return in the lo price state, while $\mathrm{N}$-debt is strictly more expensive than T-debt in that state).

Since lenders have to break even: $\left.\left(1+\rho^{n}\right)(1-\alpha) \underline{p} F \geq 1+r\right)$. Also, Tbonds investment has to satisfy $s(1-(1-\alpha) F) \leq w$. Profit are bounded by gross returns on T-bonds, which are in turn bounded above by $(1-\alpha) \frac{1+r}{1-(1-\alpha) F} w$. With $F=0$, this is clearly inferior to the best safe plan. The same is true for $F=1$, because $\alpha>\frac{1}{2}$ by (34). This concludes the proof.

Proof of Proposition 5. The following proposition and Lemma 9 directly imply Proposition 5.

Proposition 5*. If conditions (31)-(34) hold, then the implications of Lemma 5 are true.

Proof. By construction, the feasible plans in problem $\mathbf{P}(F)$ are exactly those that are fundable if everybody else chooses a risky plan. In addition, the feasible set for $\mathbf{P}(0)$ applies to two situations. First it comprises all fundable plans if everybody else chooses a risky plan and there is no bailout guarantee. Furthermore, it also comprises all fundable plans if everybody 
else chooses a safe plan, and it does so independent of the value of $\phi$. The set of feasible safe plans is the same for $\mathbf{P}(F)$ and $\mathbf{P}(0)$.

A safe plan is part of a symmetric equilibrium if and only if it solves $\mathbf{P}(0)$. Indeed, any safe plan that does not solve $\mathbf{P}(0)$ can be ruled out as an equilibrium: if it was chosen by everybody, there would be no bailout, so an individual could again have any plan from the feasible set funded (including the maximizer). Conversely, we can construct an equilibrium from any safe maximizer of $\mathbf{P}(0)$. Now since conditions (31)-(34) hold, Proposition 4 says that for $\phi=0$, there is always a safe plan solving $\mathbf{P}(0)$. We can read off the properties of such a plan from Lemma 3. This shows Part 1.

A risky plan is part of a symmetric equilibrium if and only if it solves $\mathbf{P}(F)$. Indeed, any risky plan that is feasible in $\mathbf{P}(F)$ but is not a maximizer can never be part of a symmetric equilibrium. Suppose it was, then a bailout would be expected in the good state, so an individual entrepreneur could choose any plan from the feasible set and have it funded. He could thus simply pick the maximizer. Conversely, we can construct an equilibrium from any risky maximizer of $\mathbf{P}(F)$. Now since conditions (31)-(34) hold, Proposition 4 implies that under the maintained assumptions, there is a risky plan that solves $\mathbf{P}(F)$ if and only if $F=1$. We can read off the properties of such a plan from Lemma 3. This shows Part 2.

Proof of Proposition 6. Part 1. We need to show that, under the conditions of the proposition, there is a solution $\left(q_{t}, w_{t}\right)$ to $(20)-(21)$ which satisfies the positive NPV condition on prices. It is clear that there is a solution for every set of initial conditions. Note also that, along this solution, $p_{t} \theta>(1+r) p_{t-1}$ for all $t<T$, if and only if

$$
w_{t-1}>\frac{\beta d}{c m^{s}}=: \underline{e}_{1}
$$

while, for the terminal period, $p_{T} \theta>(1+r) p_{T-1}$ if and only if

$$
w_{T-1}<\beta(1-\beta h) \hat{d}
$$

Moreover, for $t<T, w_{t}>w_{t-1}$ if and only if

$$
w_{t-1}>\left(\frac{1}{1-c}-\frac{1-h}{1-\beta h}\right)^{-1} d=: \underline{e}_{2}
$$

We have $\underline{e}_{2}>0$ by Assumptions 1 and 2. Let $\underline{e}=\max \left\{\underline{e}_{1}, \underline{e}_{2}\right\}$. Let $w_{t}\left(e_{0}\right)$ denote the solution of an economy starting at $w_{0}=e_{0}>\underline{e}$. This solution 
increases over time. Finally, to ensure (45a), let $\hat{d}>\underline{d}\left(e_{0}, T\right)=\beta^{-1}(1-$ $\beta h)^{-1} w_{T-1}\left(e_{0}\right)$.

Part 2. We show that, for appropriately chosen lower bounds $w_{p}$ and $w_{q}$, the conditions $p_{t}>p_{t-1}$ and $q_{t}>q_{t-1}$ are equivalent to $w_{t-1}>w_{p}$ and $w_{t-1}>w_{q}$, respectively. Since $w_{t}$ is increasing over time, by Part 1, this implies Part 2. > From (20) we have that along a solution output is increasing when $w_{t-1}[m(\theta-1)]>d$. For prices, we have that $p_{t}>p_{t-1}$ for $t<T$ along a solution if and only if $m(\eta h-\theta(\eta-1)) w_{t-1}>d$. Assumption 3 implies that the terms multiplying $w_{t-1}$ are positive. Thus, the lower bounds $w_{p}$ and $w_{q}$ are given by

$$
w_{p}:=d m^{-1}[\eta h-\theta(\eta-1)]^{-1}, \quad w_{q}:=d[m(\theta-1)]^{-1}
$$

Proof of Proposition 7. We begin by constructing a candidate 'lucky path'. Let the bound $\underline{e}$ be the bound from Part 1 of Proposition 6. Pick an $e_{0}>\underline{e}$ and let $w_{t}\left(e_{0}\right)$ denote the solution to the safe equilibrium difference equation (21). Select $\underline{\tau}$ such that $\underline{\tau}-1$ is the smallest $t$ such that $w_{t}\left(e_{0}\right)$ satisfies (26).

We will construct a path where $\left(q_{t}, w_{t}\right)$ evolve according to a safe equilibrium until time $\underline{\tau}-2$, and then according to a risky equilibrium until $T-1$. The last step, from $T-1$ to $T$, is again according to a safe equilibrium transition. For any $T$ we can define a lucky path as the unique solution, for given $w_{0}=e_{0}$ and $q_{0}$, to

$$
\begin{array}{rlrl}
q_{t} & =\theta \frac{m_{t-1} w_{t-1}}{m_{t-1} w_{t-1}+d} q_{t-1} & & ; t \leq T \\
\frac{1-\eta_{t}}{1-c} w_{t} & =d-\gamma_{t-1} m_{t-1} w_{t-1} & & ; t<T \\
w_{T} & =\hat{d}-h m^{s} w_{T-1} &
\end{array}
$$

where for $t \leq \underline{\tau}-2$, we have $m_{t}=m^{s}, \eta_{t}=\eta^{s}$ and $\gamma_{t}=h$. Meanwhile, for $t=\{\underline{\tau}-1, \ldots, T-2\}, m_{t}=m^{r}, \eta_{t}=\eta^{s}$ and $\gamma_{t}=\alpha^{-1} h$. To prove that this path is an equilibrium, we need to show that for $t=\{\underline{\tau}-1, \ldots, T-2\}$, conditions (31), (32) and (33) hold, with prices $p=p_{t}, \bar{p}=\frac{d+m_{t+1} w_{t+1}}{q_{t}}$ and $\underline{p}=\frac{d+m^{s} e}{q_{t}}$. If this is the case, the transition from $t$ to $t+1$ is indeed consistent with a risky equilibrium, by Proposition $5^{*}$. Similarly, we have to show that for $t \leq \underline{\tau}-2$ and $t=T-1$ (31) holds, but for $\alpha=1$. 
We know that the condition for safe equilibria is equivalent to a lower bound on $w_{t}$. Some algebra reveals that the conditions ensuring existence of a risky equilibrium at $t$ also have this structure. In particular, (31) holds at time $t$ if and only if

$$
\left(\alpha \gamma_{t-1} \frac{\eta_{t}}{\eta_{t}-1}-\beta^{-1}\right) m_{t-1} w_{t-1} \geq \alpha \frac{d(1-c)}{\eta_{t}-1}-(1-\alpha)\left(m^{s} e+d\right)
$$

Condition (32) holds if and only if

$$
d+m^{s} e \leq \gamma_{t-1} m_{t-1} w_{t-1}
$$

Condition (33) is equivalent, along the candidate path, to

$$
\left(\frac{\alpha^{-1} h}{1-\alpha} m_{t-1}-\frac{\gamma_{t-1} \eta_{t-1}}{\eta_{t}-1} m_{t}\right) w_{t-1} \geq-\frac{d}{\eta_{t}-1}
$$

We also have that $w_{t}>w_{t-1}$ along a solution if and only if

$$
\left(1-\eta_{t}+\gamma_{t-1} \eta_{t-1}\right) w_{t-1}>(1-c) d
$$

If $\alpha$ goes to one, all the possible lower bounds for $w_{t-1}$ required by (52) converge to a number smaller or equal than $\underline{e}$. Since $w_{0}>\underline{e}$, it follows that for $\alpha$ close enough to one, $w_{t}$ is increasing over time. Similarly, the lower bounds required by (49) converge to a number smaller or equal than $\underline{e}$. It follows that (49) holds for every $t$ if $\alpha$ is close to one. Moreover, (50) holds at time $\underline{\tau}$ for $\alpha$ close to one, because $w_{\underline{\tau}-1}\left(e_{0}\right)$ satisfies $(26)$ by construction. Since $w_{t}$ is increasing, (50) then holds for all $t$, up to $T-1$. Finally, if $\alpha$ is close enough to one, the term multiplying $w_{t-1}$ on the left hand side of (51) is positive. This implies that (51) holds for all $t$. We have thus ensured that the candidate solution is consistent with a risky equilibrium in $t=\{\underline{\tau}-1, \ldots, T-2\}$. Finally, to ensure that the path is consistent with a safe equilibrium in period $T-1$ we pick $\hat{d}$ large enough such that (45a) holds (i.e., $\left.\hat{d}>\underline{d}\left(e_{0}, \alpha, T\right)\right)$. This established parts 1 and 2 .

To show that prices and output rise before the crisis, we use an argument analogous to the one we used to show that (31) holds. In particular, some algebra reveals that the conditions for increasing prices and output have the form $w_{t}>w_{p}(\alpha)$ and $w_{t}>w_{q}(\alpha)$, respectively, where

$$
w_{p}:=d m_{t-1}^{-1}\left[\eta_{t} \gamma_{t-1}-\theta\left(\eta_{t}-1\right)\right]^{-1}, \quad \quad w_{q}:=d\left[m_{t-1}(\theta-1)\right]^{-1}
$$


Note that $w_{p}(\alpha) \rightarrow w_{p}$ and $w_{q}(\alpha) \rightarrow w_{q}$ as $\alpha \rightarrow 1$. Therefore, when $\alpha$ is close to one, if prices and output are increasing during the safe stage, they are also increasing during the risky stage. Since the growth rate of $w_{t}$ is bounded away from 1, we know that prices and output will begin to rise once internal funds are large enough. Since we are starting the risky stage in a state where the latter conditions hold, and since $w_{t}$ is increasing over time, part 3 is established by picking a sufficiently large lower bound on $T$ $\left(\underline{T}\left(e_{0}, \alpha\right)\right)$.

After a crisis occurs, the economy reverts to $w_{t}=e$. We know from Proposition 6 that a safe equilibrium with this initial condition (and any initial value for $q$ ) exists. Consider the case where $t=\{\tau, \ldots, T-1\}$ is a crisis period. Since $q_{t}>q_{t-1}$ for $t \geq \tau$, we have

$$
p_{t}=\frac{d+m^{s} e}{q_{t}}<\frac{d+m_{t-1} w_{t-1}}{q_{t-1}}=p_{t-1}
$$

so that a crisis involves a real depreciation. In addition, $\frac{q_{t+1}}{q_{t}}=\theta \frac{m^{s} e}{d+m_{s} e}<1$ under the stated condition. This establishes part 4.

Proof of Corollary 8. This result follows directly from the dynamic system in the proof of Proposition 7 and the definition of $m$

\section{References}

[1] Aghion, Philippe, Philippe Bachetta, and Abhijit Banerjee (2000), "Capital Markets and the Instability of Open Economies," mimeo, Study Center Gerzensee.

[2] Bank for International Settlements (1998), Report of the Working Group on International Financial Crises, Basle.

[3] Bernanke, Ben and Mark Gertler (1989), "Agency Costs, Collateral and Business Fluctuations." American Economic Review 79, 14-31.

[4] Bernanke, Ben, Mark Gertler and Simon Gilchrist (1999), "The Financial Accelerator in a Quantitative Business Cycle Framework." NBER working paper 6455 . 
[5] Burnside, Craig, Martin Eichenbaum and Sergio Rebelo, (2000), "On the Fundamentals of Self-Fulfilling Speculative Attacks," NBER working paper 7554.

[6] Caballero, Ricardo and Arvind Krishnamurthy (1999), "Emerging Markets Crises: An Asset Markets Perspective," mimeo, MIT.

[7] Calvo, Guillermo (1998), "Capital Flows and Capital Market Crises: The Simple Economics of Sudden Stops," Journal of Applied Economics, pp 35-54.

[8] Calvo, Guillermo and Carlos Vegh (2000), "Inflation Stabilization and BoP Crises," Handbook of Macroeconomics, North Holland.

[9] Chang Roberto and Andres Velasco (1998), "Financial Crises in Emerging Markets: A Canonical Model," NBER working paper 6606.

[10] Cole, Harold and Timothy Kehoe (1999), "Self-Fulfilling Debt Crises," mimeo, University of Minnesota.

[11] Corsetti, Giancarlo, Paolo Pesenti and Nouriel Roubini (1998). "Paper Tigers," mimeo, New York University.

[12] Drazen, Allan and Elhanan Helpman (1990), "Inflationary Consequences of Anticipated Macroeconomic Policies," Review of Economic Studies, $57,147-166$.

[13] Froot, Kenneth, David Scharfstein and Jeremy Stein (1993), "Risk Management: Coordinating Corporate Investment and Financing Policies," Journal of Finance, 48(5), December 1993, pages 1629-58.

[14] Gourinchas, Pierre Olivier, Oscar Landerretche, and Rodrigo Valdes (1999), "Lending Booms: Some Stylized Facts," mimeo, Princeton University.

[15] Holmstrom, Bengt and Jean Tirole (1997), "Financial Intermediation, Loanable Funds and the Real Sector." Quarterly Journal of Economics v 112, 663-691.

[16] Kasa, Kenneth (1998), "Borrowing Constraints and Asset Market Dynamics: Evidence From the Pacific Basin," mimeo, Federal Reserve Bank of San Francisco. 
[17] Krueger, Anne and Aaron Tornell, "The Role of Bank Lending in Recovering From Crises: Mexico 1995-1998," NBER working paper 7042.

[18] Krugman, Paul (1998), "Bubble, Boom, Crash: Theoretical Notes on Asia's Crisis." Working Paper, MIT.

[19] Krugman, Paul (1999), "Balance Sheets, The Transfer Problem, and Financial Crises, mimeo, MIT.

[20] Ljungqvist, Lars (1995), "Deposit Insurance, Asset Accumulation and Asset Price Volatility", Working Paper, SUNY Buffalo.

[21] McKinnon, Ronald and Huw Pill (1998), "International Overborrowing: A Decomposition of Credit and Currency Risks." Working Paper, Stanford.

[22] Mishkin, Frederic (1998), "International Capital Movements, Financial Volatility and Financial Instability." NBER Working Paper no 6390.

[23] Obstfeld, Maurice (1986), "Rational and Self-fulfilling Balance of Payments Crises," American Economic Review 76(1), 72-81.

[24] Sachs, Jeffrey, Aaron Tornell and Andres Velasco (1996). "Financial Crises in Emerging Markets: The Lessons From 1995," Brookings Papers on Economic Activity.

[25] Schneider, Martin (1999), "Borrowing Constraints in a Dynamic Model of Bank Asset and Liability Management", mimeo, University of Rochester

[26] Schneider, Martin and Aaron Tornell (1999), "Lending Booms and Asset Price Inflation," working paper, Harvard University.

[27] Tornell Aaron (1999), "Common Fundamentals in the Tequila and Asian Crises," NBER working paper 7193. 
Manufacturing

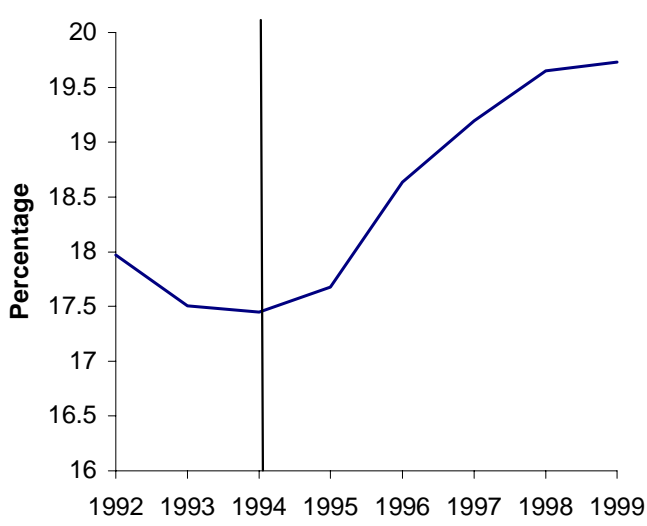

19921993199419951996199719981999

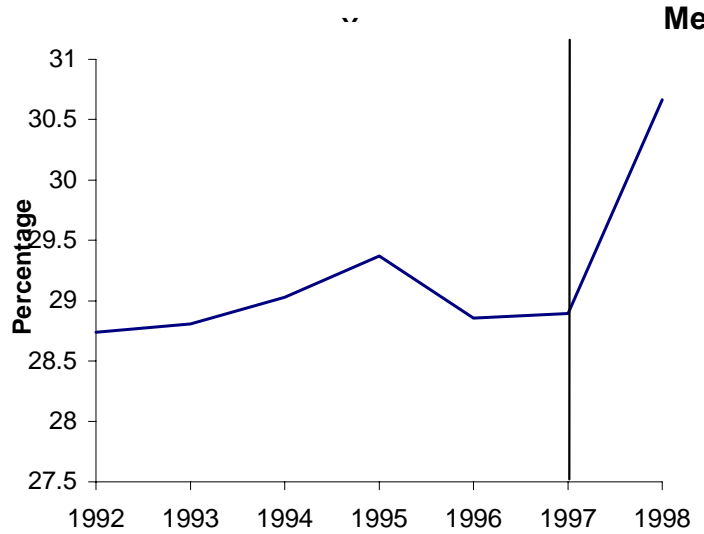

Korea

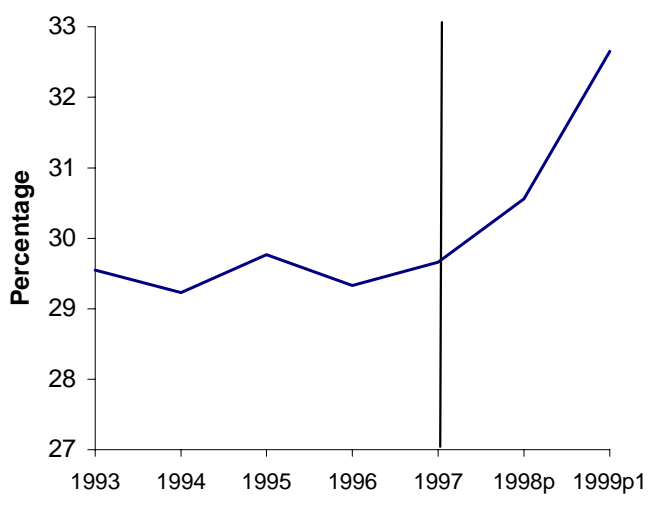

Construction

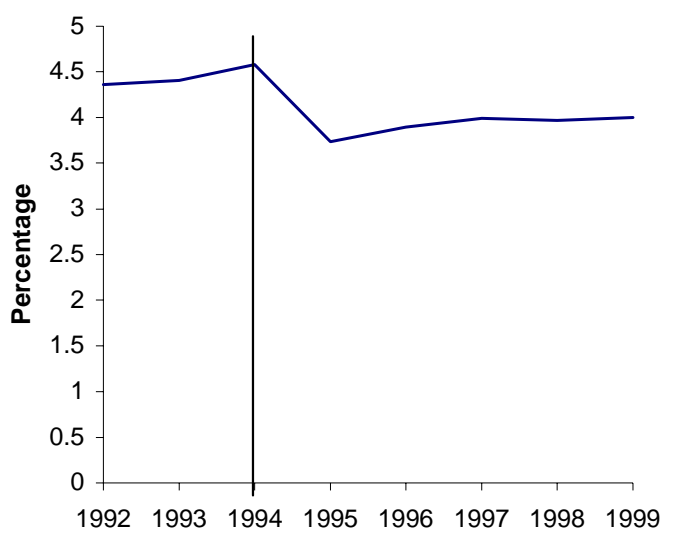

Mexico
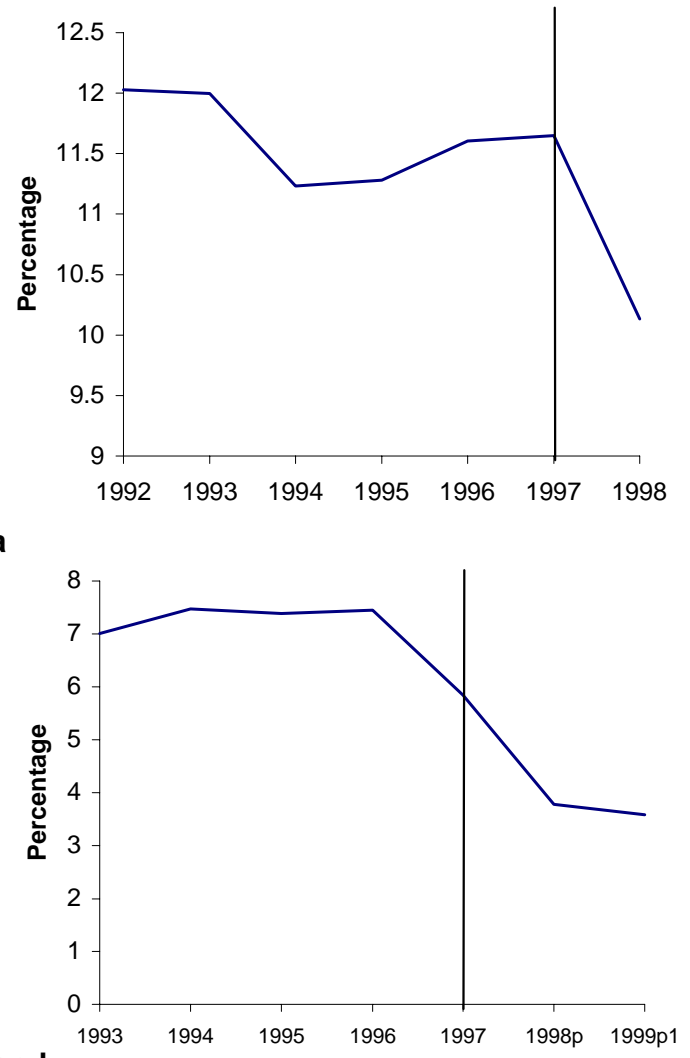

Thailand

Source: INEGI, Mexico; Central Bank of Korea; National Accounts Division, NESDB Thailand

Figure 1: Tradables and Nontradables Sectors (percent of GDP) 
Real Credit from the Banking System

to the Private Sector $(1992=100)$
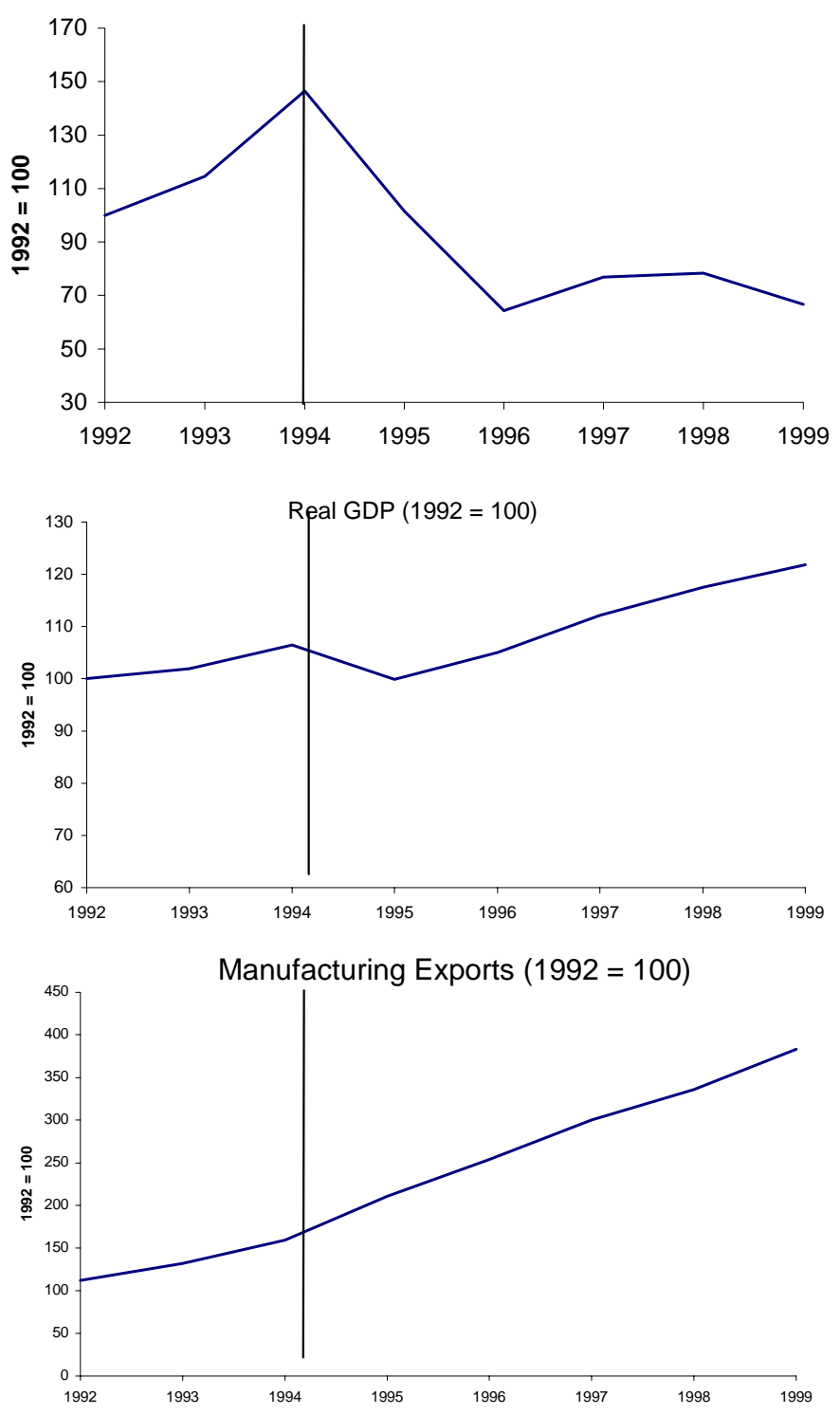

Source: IMF, International Financial Statistics and Banco de Mexico

Figure 2: Mexico: 1992-1999 


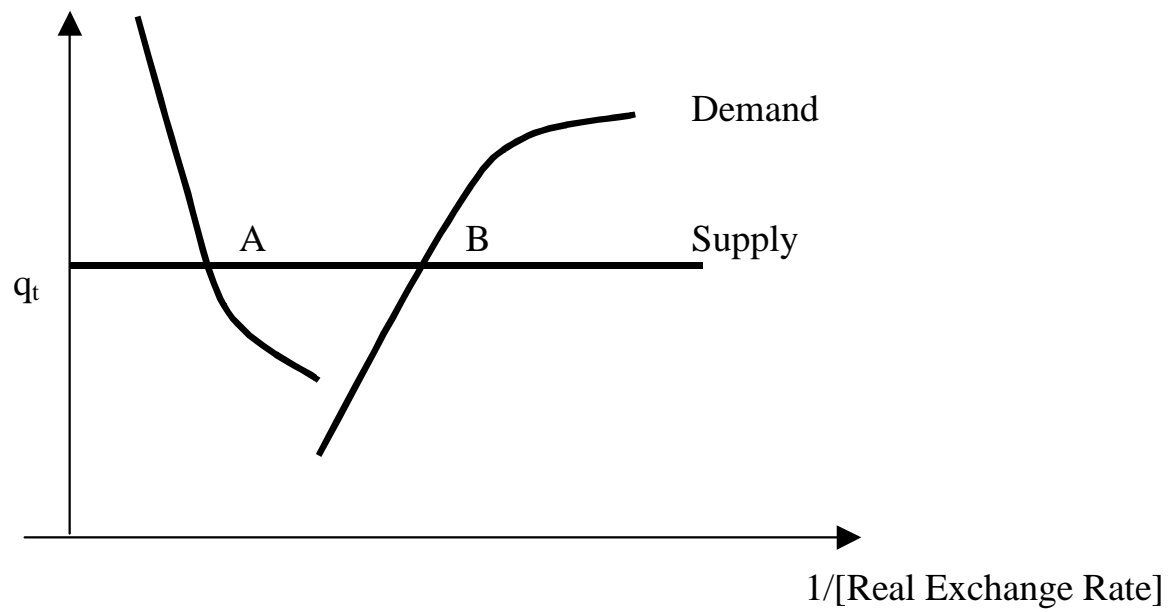

Figure 3: Market Equilibrium of Nontradables 

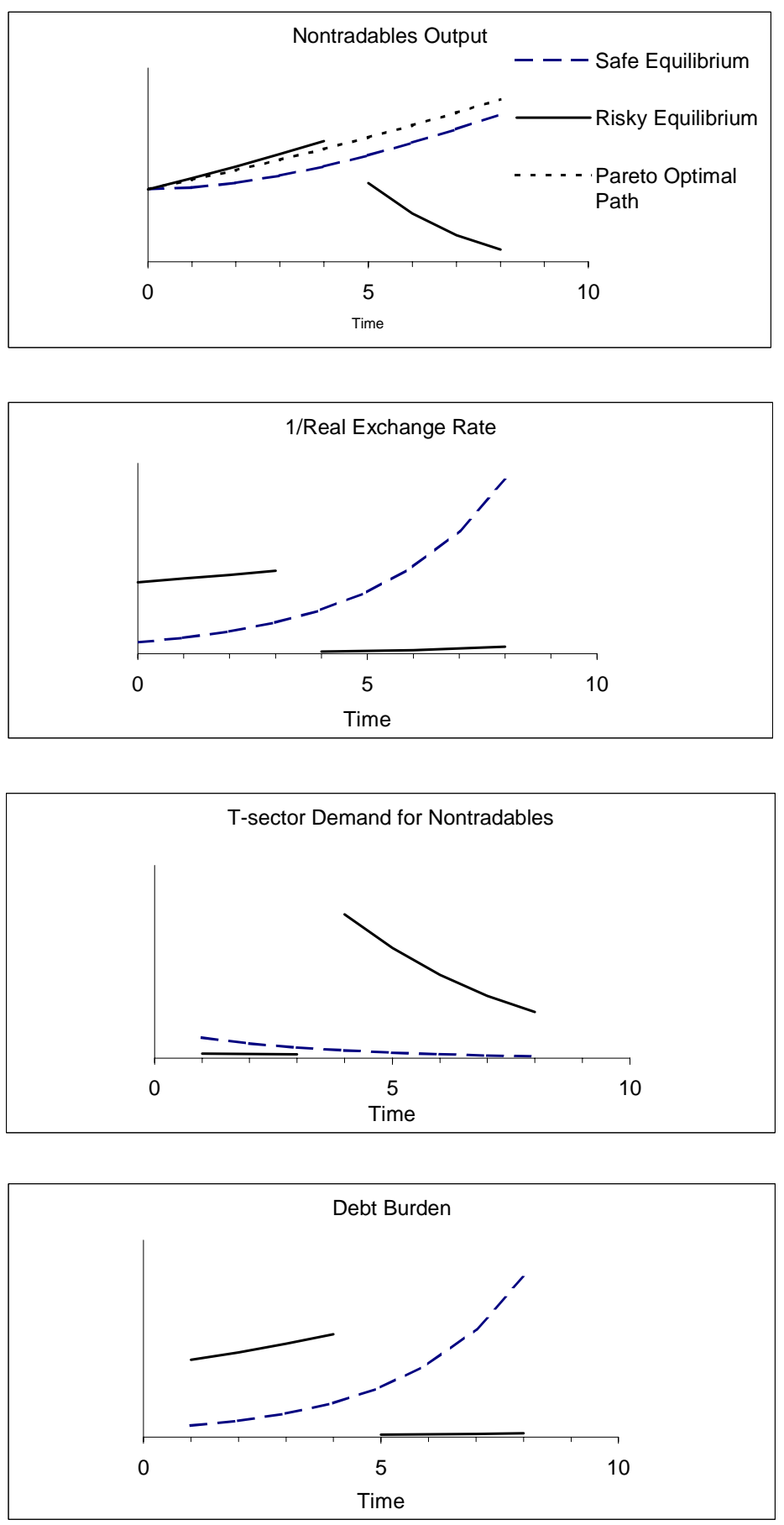

Note: The parameters used are e $=8.1417, \mathrm{q} \_0=5, \mathrm{w} \_\mathrm{cr}=1.6417$, alpha $=0.9598$, theta $=1.0527, \mathrm{~d}=8, \mathrm{~g}=0.7783$, beta $=0.9434, \mathrm{~h}=1.01, \mathrm{~T}=8, \mathrm{~d} \_$hat $=\mathrm{d}^{*}(1+\mathrm{g})^{\wedge} \mathrm{T}$.

58

Figure 4: A Boom-Bust Episode 